\title{
The effects of thermal and compositional stratification on the ignition and duration of homogeneous charge compression ignition combustion
}

Janardhan Kodavasal $^{\mathrm{a}^{*}}$, George A. Lavoie ${ }^{\mathrm{a}}$, Dennis N. Assanis ${ }^{\mathrm{b}}$, and Jason B. Martz

a. Walter E Lay Automotive Laboratory, University of Michigan, Ann Arbor, MI 48109, USA

b. Stony Brook University, Stony Brook, NY 11790, USA

Janardhan Kodavasal:

*corresponding author (currently with Argonne National Laboratory):

Previous Address: 1231 Beal Avenue, 2032 AL, Ann Arbor, MI - 48109

Present Address - 9700 S. Cass Ave., Bldg. 362, Argonne, IL - 60439

Email - jkodavasal@anl.gov

Telephone- +1(734)546-8210

Fax- +1(630)252-3443

George A. Lavoie : glavoie@umich.edu

Dennis N. Assanis : dennis.assanis@ @stonybrook.edu

Jason B. Martz : jmartz@umich.edu

Type of article: Full-length

Running title: Effects of stratification on HCCI

Word-count: 6,869 


\section{The effects of thermal and compositional stratification on the ignition and duration of homogeneous charge compression ignition combustion}

In this work, the effects of thermal and compositional stratification on the ignition and burn duration of homogeneous charge compression ignition (HCCI) combustion are studied with full-cycle 3D computational fluid dynamics (CFD) simulations with gasoline chemical kinetics performed during the closed portion of the cycle, from intake valve closing (IVC). The stratification was varied through the use of negative valve overlap (NVO) and positive valve overlap (PVO) breathing strategies. To remove charge energy and phasing effects from the simulation results, the fuel mass and ignition timing were held constant, while mean composition effects were isolated from those of local stratification by maintaining the same mean oxygen concentration, fuel-oxygen equivalence ratio and charge heat capacity. Fuel was premixed with the intake to avoid potential stratification effects arising from direct injection. With NVO, the incomplete mixing of the fresh charge with the large mass fraction of product gases retained within the cylinder from the previous combustion cycle leads to a $23 \%$ increase in the preignition thermal stratification, and an order of magnitude increase in the levels of stratifications in fuel to oxygen equivalence ratio and oxygen mole fraction relative to the PVO strategy, which employs a premixed mixture of fresh and product gases. Under the conditions studied, the use of NVO resulted in a 30\% increase in the $10-90 \%$ burn duration (CA10-90) compared to the PVO condition. Two additional analyses were performed to decouple the effects of thermal and compositional stratification. The first examined the reaction space (based on the ignition delay distribution within the charge prior to ignition) for both breathing strategies to quantify the inherent reactivity stratification. The second examined the more stratified NVO case with a quasidimensional multi-zone model. These analyses revealed that under the conditions studied, HCCI reactivity and combustion duration are governed primarily by thermal stratification and are largely insensitive to compositional stratification at the time of ignition.

Keywords: HCCI; LTC, NVO; reaction space; stratification; CFD

\section{Introduction}

Homogeneous charge compression ignition (HCCI) is an advanced combustion mode for reciprocating internal combustion engines, which aims to achieve diesel-like efficiency while minimizing emissions of nitrogen oxides $\left(\mathrm{NO}_{\mathrm{x}}\right)$ and soot [1] - [4]. HCCI requires higher unburned gas temperatures than conventional spark-ignited (SI) operation [5], since combustion is initiated through chemical kinetics rather than through spark discharge. To achieve the required temperature for auto-ignition, HCCI engines typically employ an increased compression ratio, along with a means for controlling the sensible internal energy of the charge at intake valve closing (IVC), either through the retention of hot residual combustion products, or 
through the external heating of the incoming charge (intake air heaters [6], bypassing the intercooler [7]), or through a combination of these methods.

One method to achieve HCCI is with conventional positive valve overlap (PVO), with premixed fuel, air and exhaust gas recirculation (EGR) [3], [6]. This method has minimal compositional stratification within the charge owing to premixed operation [8]. Here, the intake air is typically heated to provide the thermal energy needed to achieve auto-ignition. Another method, appropriate for the control of autoignition phasing, is negative valve overlap (NVO) [9] - [14], where the exhaust valve is closed prematurely during the exhaust stroke in order to retain a large fraction of high temperature residual combustion products within the cylinder, which is then mixed with the cooler incoming fresh charge. To advance ignition timing, the charge temperature at IVC is increased by retaining higher levels of residual mass fraction through earlier closure of the exhaust valve. This strategy is particularly effective in managing hot internally recirculated exhaust gas (iEGR) on a cyclic basis, making NVO operation attractive for transient operation.

During NVO operation, hot residual gases and cooler fresh fuel-air mixture are mixed during the ignition delay period. If the mixing timescales are longer than the ignition delay, the combustion process will occur within a thermally and compositionally stratified charge, which could affect the local combustion regime. A series of direct numerical simulation (DNS) studies investigating this question have shown that combustion under HCCI conditions is chemically controlled [15] - [18]. In particular, Chen et al. [17] found that under typical HCCI engine conditions without significant stratification, unlike diesel combustion with direct injection, a reasonable approximation is that different locations in the cylinder interact only through pressure-work, with molecular mixing effects not having a large impact. The work of Bansal and Im investigating thermal and compositional stratification effects arrived at a similar conclusion [19]. Spontaneous wave-like ignition front propagation (sequential auto-ignition) [20] was observed for a case with pure thermal stratification and also for a case with uncorrelated thermal and equivalence ratio stratification, 
whereas near constant-volume combustion was observed for a case with negatively correlated thermal and equivalence ratio stratification. Finally, it was observed in one dimensional premixed flame modeling that burned gas temperatures on the order of 1400 to $1500 \mathrm{~K}$ are required to support premixed flames under HCCI conditions [21], [22]. Achieving such temperatures would require relatively high levels of end-gas reaction progress during $\mathrm{HCCI}$, with steep compositional and thermal gradients. Although flames can be supported under these conditions, the combustion mode within the compositional and thermal gradient of the flame transitions from deflagration to the spontaneous ignition front regime at end-gas thermal runaway [23]; the end-gas mass consumed by the front during the auto-ignition process was also minimal [23]. These results suggest that the chemically controlled combustion assumption employed in HCCI combustion modelling is appropriate for the modelling of this combustion process [24] - [31]. It must be noted that the CFD combustion model used in the current work also treats every cell as a homogeneous reactor, as in [24] - [31], and thus does not account for turbulence-chemistry interactions (TCI). Further, the Reynolds Averaged Navier-Stokes (RANS) approach used in this work does not capture turbulent fluctuations in the temperature and equivalence ratio fields. However, as it is shown later in this document, adopting the RANS well-mixed approach for HCCI combustion produces good results compared to experiments even for NVO cases with higher stratification, in terms of global pressure profiles and burn rates, which are the focus of this study. A more sophisticated combustion model that also accounts for TCI in conjunction with large eddy simulation (LES) could be adopted in future work.

Other researchers have experimentally investigated the implications of NVO on charge stratification and HCCI combustion. In their pioneering optical engine work, Rothamer et al. [8] compare the stratification during NVO against PVO operation with little valve overlap. They found significant thermal and compositional stratification within the charge prior to ignition with $\mathrm{NVO}$ and speculated that the enhanced stratification could extend the burn duration. However, they do not say what 
the relative importance of thermal versus compositional stratification is with respect to burn duration. Babajimopoulos et al. [28] numerically investigated the effect of accounting for both thermal and compositional stratification within computational fluid dynamics (CFD) simulations of HCCI combustion and came to the conclusion that under the conditions studied by them, neglecting compositional stratification does not affect prediction of ignition timing significantly. However, unlike the current work, their study did not examine burn rates, and did not attempt to correlate the effect of stratification to sequential autoignition and burn duration. Joelsson et al. [32] performed large eddy simulations (LES) to determine distributions resulting from NVO operation followed by multi-zone kinetics calculations. They found that under higher NVO conditions a zone with a preferred mixture composition and temperature ignited first. More recently, Olesky et al. [14] studied the effect of NVO operation on HCCI combustion duration by trading off intake air heating with NVO duration over a range of combustion phasings. They found that for a given combustion phasing, increasing the level of NVO consistently increased the $10-90 \%$ burn duration compared to operation with less NVO and elevated intake temperature. They hypothesized that the observed increase in burn duration was due to a combination of effects such as lower oxygen concentration (a chemical kinetic effect) and higher mixture specific heat (a thermodynamic effect) resulting from replacing some of the air in the charge with residual as NVO increased. They also proposed that additional thermal stratification could be generated from the higher levels of NVO, which in turn would increase the burn duration.

Olesky et al. also examined the influence of NVO, and its potential thermal and compositional stratification, on spark assisted compression ignition (SACI) combustion at constant spark timing and fueling [33]. They varied internal residual through a relatively small ( $26^{\circ}$ crank angle) adjustment in NVO. External EGR (eEGR) was adjusted in conjunction with intake air preheating to maintain constant the total residual fraction and inferred temperature at intake valve closing. The resulting variations in NVO had little to no effect on combustion, implying that the 
relative variations in thermal and compositional stratification associated with NVO were minor under these conditions. Considering the narrow range of NVO used in this study, it cannot be concluded that such effects are not important when evaluated over a much broader range of valve events.

There is presently an understanding gap in the importance of thermal and compositional stratification to the overall reactivity stratification controlling the ignition and duration of HCCI combustion under engine relevant conditions. While previous experiments have shown that stratification does indeed vary with breathing strategy [14] and also how such variations may affect HCCI combustion duration [8], mean compositional effects, such as oxygen concentration and heat capacity, are interwoven with local stratification effects in these studies. Therefore, the objective of the current work is to evaluate stratification effects, in isolation from mean composition effects, on the charge reactivity distribution and the consequent effect of this distribution on HCCI ignition conditions and combustion duration.

To this end, full-cycle CFD KIVA-3V [34] simulations are performed with fully-coupled multi-zone gasoline chemical kinetics for PVO with external EGR dilution (eEGR) and for NVO with internal exhaust gas recirculation (iEGR). Potential factors complicating the analysis, such as the localized evaporative cooling and stratification associated with direct injection [35] - [41] are avoided through the use of a premixed fuel-air mixture at the intake for the NVO condition and a premixed fuel-air-eEGR mixture at the intake for the PVO condition. Both NVO and PVO cases were configured to have the same mean composition in terms of oxygen concentration and heat capacity $\left(C_{p}\right)$, fueling and overall level of charge dilution at intake valve closing (IVC) through the respective manipulation of internal (iEGR) and external (eEGR) recirculated exhaust gas. Additional intake charge heating is used for the PVO-eEGR case to match the ignition timing of the NVO-iEGR case. Burn durations are compared for the two breathing strategies and the reaction space is analyzed to understand the impact of thermal and compositional stratification on the reactivity stratification prior to ignition. Then, using a quasi-dimensional multi-zone model, the 
thermal and compositional stratification effects are decoupled in an attempt to understand the relative importance of each stratification mode to the burn duration.

\section{CFD Model}

The CFD code KIVA-3V [34] with fully coupled multi-zone chemical kinetics [29], [30] is used for the CFD simulations in the current work. The standard law-of-the wall approach is used to model heat transfer, in conjunction with fixed component temperatures for the head $(450 \mathrm{~K})$, piston $(480 \mathrm{~K})$ and liner $(450 \mathrm{~K})$. Radiation effects are not included. The turbulence model used is the standard k- $\varepsilon$ model. The Taylor Analogy Breakup (TAB) model [42] is used to model spray breakup for the validation cases, which employ direct injection. The computational mesh is a three-dimensional (3D) mesh with moving valves that has cell sizes on the order of $1 \mathrm{~mm}$ at all times. This mesh is based on a single-cylinder fully-flexible valve actuation (FFVA) research engine at the University of Michigan, which consists of a Ricardo Hydra gasoline block with a modified head and piston with a side-mounted gasoline direct injector. Specifications of the FFVA engine and the corresponding CFD mesh used are provided in Table 1 while the computational mesh is shown in Figure 1.

The multi-zone approach is used to compute the chemical kinetics at every time-step, where the current CFD domain ( 22,000 cells near top dead center, TDC) is mapped onto a reaction space domain by grouping cells with similar thermochemical states into approximately 2000 "chemistry" zones for the kinetics calculations. Chemical kinetics are thus solved in $\sim 2000$ zones rather than $\sim 22,000$ cells, and after the chemistry calculations, new species concentrations computed in the zones are remapped onto the CFD cells for the fluid dynamic calculations. In this way both mixing and chemistry are taken into account throughout the combustion event. As mentioned earlier, TCI is not included within this model. 
The zones of the multi-zone model are defined in part with the variable $\varphi$ or "progress equivalence ratio," which was defined by Babajimopoulos et al. [29] to capture combustion progress within every cell as:

$\varphi=\frac{2 C_{-\mathrm{CO}_{2}}^{\#}+\frac{H_{-\mathrm{H}_{2} \mathrm{O}}^{\#}}{2}-z^{\prime} C_{-\mathrm{CO}_{2}}^{\#}}{O_{-\mathrm{CO}_{2}-\mathrm{H}_{2} \mathrm{O}}^{\#}-z^{\prime} C_{-C O_{2}}^{\#}}$

Here $C^{\#}, H^{\#}$ and $O^{\#}$ represent the number of carbon, hydrogen and oxygen atoms (respectively) present within a CFD cell. The subscripts $-\mathrm{CO}_{2}$ and $-\mathrm{H}_{2} \mathrm{O}$ indicate that the $\mathrm{C}, \mathrm{H}$ and $\mathrm{O}$ atoms present in products of complete combustion $\left(\mathrm{CO}_{2}\right.$ and $\mathrm{H}_{2} \mathrm{O}$ ) within the CFD cell are excluded from the computation of $\varphi$. In Eq. (1), $z$ ' is the ratio of the number of oxygen atoms to the number of carbon atoms in the fuel, which is zero for non-oxygenated hydrocarbon fuels.

The kinetics calculations use a reduced 312-species mechanism [43], based on the detailed gasoline mechanism from Mehl et al. [44], along with a matched 4component gasoline surrogate [43] with the composition shown in Table 2Error! Reference source not found.. This surrogate along with the gasoline mechanism (both detailed and reduced) has been shown to capture gasoline fuel chemistry characteristics, such as intermediate temperature heat release under boosted conditions, and has been evaluated against the HCCI engine experiments of Dec and Yang [6] by Mehl et al. [45]. Throughout this work, chemical kinetics calculations are performed only during the closed portion of the cycle, from IVC onwards.

The performance of the multi-zone model with respect to the detailed approach of solving chemistry in every cell is shown in Figure 2. The case simulated is at $2000 \mathrm{RPM}$ with $157^{\circ}$ crank angle (CA) NVO and direct fuel injection of $9.44 \mathrm{mg}$ fuel at $30^{\circ} \mathrm{CA}$ after gas-exchange TDC. This case is quite similar to the NVO-iEGR case simulated in this study, but has a higher level of stratification due to direct fuel injection. The multi-zone approach, with $5 \mathrm{~K}$ and $0.03 \varphi$ bins, captures in-cylinder pressure traces and burn duration quite well with respect to the detailed approach, and 
is similar to the zone resolution used by Som et al. [46] and Kodavasal et al. [47]. The detailed approach took close to 3.75 days to run on 80 processors totaling 7200 core-hours, while the multi-zone case ran in 20 hours on 24 processors, totaling 480 core-hours. Thus considering a 15X speed-up in simulation time with similar pressure and burn rate predictions even for a case with high levels of stratification, the multizone approach has been chosen for this study.

It is important to evaluate the ability of the CFD model to capture the effects of increased stratification by means of NVO in addition to the thermal stratification driven by wall heat loss. Two 2000 RPM cases from the Olesky et al. experiments [14] with the same fuel mass $(9.5 \mathrm{mg} / \mathrm{cycle})$ and ignition timing (crank angle at $10 \%$ mass fraction burned, CA10, $\sim 1^{\circ} \mathrm{CA}$ before TDC, bTDC) are considered here. The first has lower NVO and higher intake manifold temperature $-T_{\text {in }}\left(\mathrm{NVO}=157^{\circ} \mathrm{CA}, T_{\text {in }}\right.$ $\left.=106^{\circ} \mathrm{C}\right)$, while the second has higher $\mathrm{NVO}$ and lower $T_{\text {in }}\left(\mathrm{NVO}=179^{\circ} \mathrm{CA}, T_{\text {in }}=45^{\circ}\right.$ C). A corresponding pair of low/high NVO CFD simulations is run, with the low NVO case having $\mathrm{NVO}=157^{\circ} \mathrm{CA}$ and $T_{\text {in }}=106^{\circ} \mathrm{C}$ and the high $\mathrm{NVO}$ case having $\mathrm{NVO}=181^{\circ} \mathrm{CA}$ and $T_{\mathrm{in}}=45^{\circ} \mathrm{C}$. These simulations are initialized at $80^{\circ} \mathrm{CA}$ after TDC (aTDC), prior to the exhaust stroke of the preceding cycle, and are then run without chemistry through the exhaust and intake events, and then with chemistry from IVC all the way up to the end of combustion of the current cycle $\left(40^{\circ} \mathrm{CA}\right.$ aTDC).

Figure 3 shows the in-cylinder pressure traces from the experiments (top), which are the ensemble average of 200 consecutive cycles, and CFD simulations (bottom), for both cases, while Figure 4 shows the experimental and CFD pressure traces for the two NVO levels on top of each other for comparison. The coefficient of variation $(\mathrm{COV})$ in the net indicated mean effective pressure (IMEP) from experiments was $1.2 \%$ for the low NVO case and $0.9 \%$ for the high NVO case. Figure 5 shows the respective mass fraction burn profiles for both cases (again an average of 200 cycles being shown for experiments). It is seen in the experimental results in the top of Figure 5 that the higher NVO case has a longer 10\% to $90 \%$ mass fraction burn 
(CA10-90) duration, and that the CFD simulation (bottom) captures this trend. The ability of the CFD model to capture the pressure rise rates for a given combustion phasing (Figure 3), and also to capture the differences in burn profile going from low to high NVO (Figure 5), provides confidence in the ability of the model to capture the key behaviors in the current PVO versus NVO study. Additional comparisons of model and experiment for a range of ignition timings are described in [48].

\section{Initial conditions and results of CFD simulations comparing PVO with NVO}

Two full-cycle CFD simulations are performed for this investigation at an engine speed of 2000 RPM with constant $9.3 \mathrm{mg}$ per cycle fueling at IVC. As in the validation study, the simulations are run starting at $80^{\circ} \mathrm{CA}$ aTDC of the previous cycle; through the exhaust and intake processes, up to $40^{\circ} \mathrm{CA}$ aTDC (postcombustion) of the cycle being studied. Multiple cycles were not run in this study. The thermal and compositional boundary conditions at the inlet and outlet ports for the two simulation cases (NVO-iEGR and PVO-eEGR) were held constant, with timevarying pressure based on an experimental NVO case. It must be noted that since there is no experimental data with PVO (the minimum level of NVO in experiments is limited to around 150 degrees based on mechanical constraints), the same timevarying pressure boundary profiles were also imposed to the PVO case. The first simulation is of a baseline PVO-eEGR case which uses a PVO profile with negligible valve overlap, while the second case uses an NVO profile with a negative overlap of $157^{\circ} \mathrm{CA}$. Both valve profiles are shown as the dashed lines in Figure 6 along with representative pressure traces, while the operating conditions for the two strategies are summarized in Table 3.

Since the aim of this paper is to isolate the impact of stratification effects, both cases employ premixed fueling to simulate port fuel injection (PFI), to avoid the complicating factor of strong geometry specific fuel stratification from direct injection. In the case of NVO, the fuel is premixed with the incoming air, while for 
PVO the fuel is premixed with the incoming air and external EGR. The external EGR rate is chosen to achieve nearly identical mean composition at IVC, with total EGR $\sim 43 \%$ (the sum of the internal and external EGR fractions), defined relative to the total mass within the combustion chamber. For the NVO-iEGR case, all of the EGR is internal whereas for the PVO-eEGR case, $7 \%$ of the total charge is internal residual and $36 \%$ is external, making a total EGR of $43 \%$. Table 4 and Table 5 provide the compositions and temperatures of the residual (remaining at IVO) and intake streams for the NVO-iEGR case and the PVO-eEGR case respectively. From Table 4, it can be seen that there is a significant temperature differential of $320^{\circ} \mathrm{C}$ between the residual and intake streams for the NVO-iEGR case. Further, for this case, unlike in the PVO-eEGR case, the residual represents a significant percentage of the overall charge at IVC $(48 \%)$. This can be expected to increase initial thermal stratification of the charge at IVC compared to the PVO-eEGR case.

The overall mean composition and temperature of the charge at IVC is also provided in these tables for reference. At IVC, both cases have the same mean oxygen mole fraction $\left(\chi_{O 2} \approx 15 \%\right)$, the same mean mass based fuel-oxygen equivalence ratio $\left(\phi_{F O}=0.44\right)$ and also nearly identical specific heat capacity $\left(C_{p}=1101.1 \mathrm{~J} / \mathrm{kg}-\mathrm{K}\right.$ for PVO vs. $C_{p}=1099.6 \mathrm{~J} / \mathrm{kg}-\mathrm{K}$ for NVO). To maintain ignition timing (CA10 $1^{\circ} \mathrm{CA}$ bTDC), the NVO-iEGR case requires a lower $T_{\text {in }}$ owing to the elevated internal energy of the high level of trapped residual. As such, the NVO-iEGR case has $T_{\text {in }}=98^{\circ} \mathrm{C}$ while the PVO-eEGR case has $T_{\text {in }}=241^{\circ} \mathrm{C}$.

Figure 7 shows the in-cylinder pressure traces for both the PVO-eEGR case and the NVO-iEGR case, while Figure 8 shows the mass fraction burned profiles for the two cases magnified to highlight the differences in the $10-90 \%$ burn durations. While both cases have a similar ignition timing (CA10) as shown in Figure 8, the NVO-iEGR case has a lower pressure rise rate and lower peak pressure (Figure 7). The CA10-90 burn duration for the NVO-iEGR case is $7.2^{\circ} \mathrm{CA}$, which represents a $30 \%$ increase over the $5.5^{\circ} \mathrm{CA} 10-90$ of the PVO-eEGR case. 


\section{Reaction space analysis methodology}

The CFD results show an increase in burn duration going from PVO to NVO with the same mean composition and ignition timing. The stratification in mixture reactivity must be quantified in order to develop an understanding of the burn duration variations observed here. To do so, the iso-octane ignition delay expression of $\mathrm{He}$ et al. [49] is adopted as the reactivity metric for the current work, where a shorter ignition delay signifies a more reactive mixture. When evaluated over the local thermodynamic states (i.e. the "reaction space") of the cylinder domain, the resulting distribution of ignition delays serves as an indicator of the charge's "reactivity stratification." The He et al. expression is as follows:

$\tau_{i g n}=1.3 \times 10^{-4} \cdot P^{-1.05} \cdot \phi_{F O}^{-0.77} \cdot \chi_{O_{2}}^{-1.41} \cdot \exp (33700 / R T)$

where $\tau_{\text {ign }}$ represents the ignition delay in milliseconds, $P$ represents the pressure in atmospheres, $\phi_{F O}$ represents the fuel-oxygen equivalence ratio, $\chi_{O 2}$ represents the oxygen mole percentage, $R$ is the universal gas constant in cal/K-mol and $T$ is the temperature in Kelvin. The dimensions used to represent the reaction space follow directly from the right-hand side of Eq. (2), where the variables $T, \phi_{F O}$ and $\chi_{\mathrm{O} 2}$ represent the reaction space dimensions. While more complex ignition delay expressions are available [50], this simpler expression in a pure Arrhenius form is preferred for the clarity it offers regarding the relative importance of the key variables. The He et al. ignition correlation is valid for iso-octane over a range of naturally aspirated conditions, and has been successfully employed to model gasoline HCCI ignition ([7], [51]). To determine if this correlation is appropriate for the analysis within the current work, single-zone, adiabatic constant volume ignition delay computations were performed using the 312-species gasoline mechanism and surrogate over a range of temperatures near the pre-ignition point of $10^{\circ} \mathrm{CA} \mathrm{bTDC}$ based on the NVO-iEGR and PVO-eEGR cases studied. A representative in-cylinder pressure of 24 bar was used, while the composition for these computations was taken 
to be representative of the mean composition of the PVO-eEGR and NVO-iEGR cases, with $\phi_{F O}=0.44$ and $\mathrm{RGF}=43 \%$. The ignition delays from the constant volume ignition delay calculations (taken as the time to $10 \%$ mass fraction burned) are shown alongside the ignition delay predictions from the He et al. correlation for the same conditions in Figure 9. It can be clearly seen that under these conditions the correlation predictions agree fairly well with those from the homogeneous reactor simulations for $T>1000 \mathrm{~K}$. Significant deviation from linear behavior, which is not captured by the ignition delay correlation, is shown by the gasoline kinetics when temperatures are lower than $1000 \mathrm{~K}$. From the CFD simulations just prior to ignition, more than $\sim 90 \%$ of the charge mass is hotter than $1000 \mathrm{~K}$ (shown later in Figure 14). The He et al. correlation is therefore a good qualitative indicator of reactivity within the cylinder pre-ignition, and will be used in what follows.

\section{Analysis of the pre-ignition reaction space from CFD simulations}

The pre-ignition reaction space is analyzed for the NVO-iEGR and PVOeEGR cases in an effort to understand the causes for the difference in burn duration between the two cases. To do this, non-reacting CFD simulations, corresponding to the reacting NVO-iEGR and PVO-eEGR simulations in Section 4, are performed starting at $80^{\circ} \mathrm{CA}$ aTDC of the previous cycle; through the exhaust and intake processes and up to $10^{\circ} \mathrm{CA}$ bTDC (pre-ignition) of the cycle being studied. The preignition reaction space at the pre-ignition crank angle is then visualized in Figure 10 by grouping individual CFD cells into bins based on $T$ and $\phi_{F O}$ which are colored by $\chi_{O 2}$ to quantify the compositional and thermal stratification.

The charge thermal stratification at $10^{\circ} \mathrm{CA}$ bTDC, which is based on two standard deviations $(2 \sigma)$ in charge temperature, is $78 \mathrm{~K}$ for the PVO-eEGR case and $96 \mathrm{~K}$ for the NVO-iEGR case or $7.4 \%$ and $9.1 \%$ normalized to the respective mean temperatures (1058 K for PVO-eEGR and $1053 \mathrm{~K}$ for NVO-iEGR). Visually, the stratification of the PVO-eEGR case in both composition dimensions appears 
negligible in Figure 10. For the NVO-iEGR case however, stratification can be visually observed in both $\phi_{F O}$ as well as $\chi_{O 2}$. The $2 \sigma$ stratification in $\phi_{F O}$ is 0.004 ( $0.9 \%$ normalized to mean $\phi_{F O}$ ) for the PVO-eEGR case and 0.040 ( $9.1 \%$ normalized to mean $\left.\phi_{F O}\right)$ for the NVO-iEGR case. The $2 \sigma$ stratification in $\chi_{O 2}$ is $0.12 \%(0.8 \%$ normalized to mean $\left.\chi_{O 2}\right)$ for the PVO-eEGR case and $1.34 \%$ (8.9\% normalized to mean $\left.\chi_{\mathrm{O} 2}\right)$ for the NVO-iEGR case. Compositional stratification increases significantly for the NVO case compared with the PVO case, while thermal stratification increases more modestly.

To better understand the relation between the thermal and compositional stratification for both strategies, the mean values of $\phi_{F O}$ and $\chi_{O 2}$ with respect to temperature are visualized in Figure 11 and Figure 12. This is done by computing the mean values of $\phi_{\mathrm{FO}}$ and $\chi_{\mathrm{O} 2}$ of all CFD cells within a given temperature range. From these figures, it can be seen for the PVO case that there is negligible variation in composition $\left(\phi_{\mathrm{FO}}\right.$ and $\left.\chi_{\mathrm{O} 2}\right)$ with respect to temperature, whereas for the NVO case both $\phi_{F O}$ and $\chi_{O 2}$ are negatively correlated to the stratification in temperature, with the hotter regions (composed of burned product gases from the previous cycle) having a lower $\phi_{F O}$ and lower $\chi_{O 2}$ than the colder regions, which have higher fuel to oxygen equivalence ratios and less residual dilution.

Figure 13 shows a scatter-plot of the ignition delay from the $\mathrm{He}$ et al. correlation as a function of $1000 / T$ in every CFD cell from non-reacting CFD simulations of the PVO-eEGR and NVO-iEGR cases at $10^{\circ} \mathrm{CA}$ bTDC. The slight spread in ignition delay at a given temperature for the NVO-iEGR case is associated with the compositional stratification.

Figure 14 shows the increased thermal stratification associated with NVO operation in the cumulative charge temperature distribution for both the PVO-eEGR and NVO-iEGR cases, and Figure 15 shows the temperature distribution as a probability distribution function based on mass percentage. Note that in both Figure 14 and Figure 15, the temperature axis ( $x$-axis) is reversed, i.e., goes from higher temperatures to lower temperatures. Note in Figure 14 that the leading edge of the 
temperature distribution is hotter for the NVO case, even though both cases ignite at the same time, showing that reactivity is not purely a function of temperature. There is a $23 \%$ increase in pre-ignition thermal stratification for the NVO-iEGR case based on standard deviation in temperature ( $2 \sigma T=96 \mathrm{~K}$ for NVO vs. $2 \sigma T=78 \mathrm{~K}$ for PVO).

To understand how this increased thermal stratification affects the reactivity stratification, the cumulative distribution of reactivity (in terms of ignition delay computed in every CFD cell with the He et al. correlation) is visualized prior to ignition (at $10^{\circ} \mathrm{CA}$ bTDC) in Figure 16. From Figure 16, it can be seen that the ignition delays for the most reactive $10 \%$ of the charge mass are roughly matched, beginning at the high temperature leading edge of the distributions in Figure 13. This is an outcome of ignition timing match for the two cases (see Figure 8). However, it can be noted in Figure 16 that the reactivity in the later igniting regions of the charge is not well matched, with the NVO-iEGR case having longer ignition delays compared to the PVO-eEGR case in the less reactive portions of the charge, hence a larger overall reactivity stratification.

To remove the impact of compositional stratification on the overall reactivity stratification for the NVO-iEGR case, the ignition delay was again computed in every CFD cell with the cell temperature, however, the mean $\phi_{F O}$ and $\chi_{O 2}$ of the cylinder were used instead of the local cell values. This case, called "NVO-iEGR-mean comp" effectively neglects the effects of compositional stratification while maintaining those of thermal stratification. Figure 17 shows the computed reactivity stratification, again based on non-reacting CFD simulations at $10^{\circ} \mathrm{CA}$ bTDC, for the PVO-eEGR, NVOiEGR and NVO-iEGR-mean comp cases. It can be seen from Figure 17 that neglecting compositional stratification (NVO-iEGR-mean comp case) slightly increases the overall reactivity stratification compared to the NVO-iEGR case. As the negative correlation of thermal and compositional stratification is removed in the mean comp case, the hotter regions no longer have lower $\phi_{\mathrm{FO}}$ and $\chi_{\mathrm{O} 2}$ than the colder regions, which in turn no longer have higher fuel to oxygen equivalence ratios and less residual dilution relative to the hotter regions. Therefore, the ignition of the hotter 
regions advances in the mean comp case, while the colder regions ignite later. Overall however, it can be seen that thermal stratification continues to dominate the reactivity stratification during NVO operation.

\section{Decoupling thermal and compositional stratification effects on burn duration}

The current analysis of the reaction space is only applicable to pre-ignition conditions and is not capable of capturing the evolution of reactivity that may occur during the actual combustion event. Once ignition occurs, the most reactive regions of the charge burn and expand; they in turn compress the less reactive regions and increase their temperatures, causing the overall reactivity distribution to evolve with global reaction progress. Without this compression process, the CA10-90 durations (time between CA10 and the $90 \%$ mass fraction burned point, CA90) shown in Figure 17 would be $\sim 30$ to $50^{\circ} \mathrm{CA}$ (assuming instantaneous combustion of each parcel in the distribution), rather than the 5.5 $-7.2^{\circ} \mathrm{CA}$ shown in Figure 8. The degree of work transferred during this process depends upon mixture properties [48], [52], which vary locally between the cases. Therefore, to extend the insights gained from analyzing the pre-ignition reactivity, a quasi-dimensional multi-zone model (Quasi-D for brevity) developed by Kodavasal et al. [31] is employed as a diagnostic tool to decouple the effects of thermal from those of compositional stratification.

The Quasi-D model uses approximately 50-200 Lagrangian zones to represent the cylinder domain. It is similar to previous approaches developed by Aceves et al. and Babajimopoulos et al. [24] - [28]. Each closed and adiabatic homogeneous zone has its own temperature and composition; multiple zones are used to replicate the effect of stratification. While there is no heat or mass exchange between the zones or the surroundings, the zones interact through boundary work, expanding or contracting to satisfy the assumption of uniform pressure throughout the cylinder domain, and the

sum of the zone volumes at any crank angle is equal to the total cylinder volume determined from crank-slider kinematics. 
To initialize the Quasi-D model, a non-reacting CFD simulation is run starting at $80^{\circ} \mathrm{CA}$ aTDC of the previous cycle; through the exhaust and intake processes, up to $10^{\circ} \mathrm{CA}$ bTDC (pre-ignition) of the cycle being studied. The pre-ignition CFD domain is then binned in terms of $T, \chi_{O 2}$ and $\phi_{F O}$ so that the $\Delta T_{\text {bin }}<5 \mathrm{~K}$, $\Delta \chi_{O 2 b i n}<2 \%$ and $\Delta \phi_{F O}<0.05$. This resolution within the "reaction-space", spanned by $T, \phi_{F O}$ and $\chi_{O 2}$ results in the creation of 55 bins for the PVO-eEGR case and 177 bins for the NVO-iEGR case. Every bin from the non-reacting CFD simulation is then used to create a corresponding zone for the Quasi-D model, where species masses and temperature from each CFD bin are mapped onto the corresponding Quasi-D zone. Thus the non-reacting CFD calculation is used only to initialize the Quasi-D model which then solves chemical kinetics. At this point, the heat transfer is deactivated for each zone consistent with the closed zone formulation.

Three simulations using the Quasi-D model are performed in the current work. The first two simulations for PVO-eEGR and NVO-iEGR are initialized as described above. A third diagnostic simulation, "NVO-iEGR-mean comp" is also conducted, where the compositional stratification is eliminated while thermal stratification is maintained corresponding to the NVO-iEGR CFD simulation. This is achieved by mapping the initial mean composition within the CFD domain onto all the zones within the Quasi-D model.

Figure 18 shows the magnified burn profiles for the three cases. Note that the Quasi-D results successfully replicate the corresponding CFD cases for NVO-iEGR and PVO-eEGR as shown in Figure 8. More importantly, it may be seen that eliminating the compositional stratification generated by NVO, as done in the NVOiEGR-mean comp case, does not significantly affect the overall burn profile. Neglecting compositional stratification (NVO-iEGR-mean comp) increases the burn duration only marginally compared to the NVO-iEGR case. This results from the negative correlation between the thermal and compositional stratification for the NVO case and is in line with the reactivity distributions shown in Figure 17, which show that neglecting compositional stratification increases the pre-ignition reactivity 
stratification. Overall, these results show that thermal stratification is much more important than compositional stratification under these NVO conditions.

\section{$7 \quad$ Summary and conclusions}

In this work, the effects of thermal and compositional stratification on HCCI ignition and combustion duration are determined under engine relevant conditions. Full-cycle CFD simulations with detailed chemical kinetics are used to predict the stratification resulting from $\mathrm{NVO}$ and PVO operation. The effects of global composition are isolated from local stratification effects by matching the mean composition in terms of oxygen concentration, fuel-oxygen equivalence ratio and heat capacity during the simulation of the two valve strategies. Fueling and ignition timing are also held constant between the cases. The following observations and conclusions can be drawn from the current work:

1. The CFD simulations predict a significant increase in compositional and thermal stratification for operation with NVO relative to PVO. Much of the increase in stratification with NVO results from the retention of high levels of product gases from the previous cycle which do not completely mix with the incoming fuel and air of the current cycle.

2. A $30 \%$ increase in the $10-90 \%$ burn duration was predicted for NVO compared to PVO resulting primarily from a $23 \%$ increase in thermal stratification (based on $2 \sigma T$ ) with NVO operation. An analysis of the pre-ignition reaction space using the $\mathrm{He}$ et al. ignition delay correlation indicates that for the thermal and compositional stratification associated with the NVO and PVO systems studied here, thermal stratification dominates the HCCI reactivity stratification.

3. The compositional stratification in $\phi_{F O}$ and $\chi_{O 2}$ with $\mathrm{NVO}$ is negatively correlated to thermal stratification for the premixed fueling strategy employed here. Although minor, this compositional stratification slightly diminishes the overall reactivity stratification. 
4. A Quasi-D multi-zone model was employed to decouple the simultaneous effects of thermal and compositional stratification during HCCI combustion with premixed fueling. Burn durations were little changed for simulations with constant initial thermal stratification performed both with and without compositional stratification corresponding to NVO operation. The predictions with this model are consistent with those from the reactivity stratification analysis. It can be concluded that under the conditions studied, the burn duration is a strong function of thermal stratification with minimal dependence on compositional stratification.

\section{ACKNOWLEDGMENTS}

The authors would like to acknowledge Dr. Aris Babajimopoulos of Volvo Cars, Sweden, as well as Prof. Hong Im, Prof. Jim Driscoll and Prof. Claus Borgnakke of the University of Michigan for valuable insights and recommendations. We thank Dr. Laura Olesky for sharing experimental HCCI data and Dr. Rob Middleton for parallelizing the chemistry calculations in the CFD code. We are grateful to Dr. Li Jiang, Jeff Sterniak, Hakan Yilmaz and Oliver Miersch-Wiemers of Bosch Gasoline Systems for their support and Dr. Dave Cook, Dr. Sergei Chumakov and Dr. Aleksandar Kojic of Bosch Research and Technology Center for facilitating the use of their high-performance computing cluster. Dr. Randy Hessel of the University of Wisconsin developed the CFD mesh used in this work.

This material is based upon work supported by the Department of Energy [National Energy Technology Laboratory] under Award Number(s) DE-EE0003533. This work is performed as a part of the ACCESS project consortium (Robert Bosch LLC, AVL Inc., Emitec Inc., Stanford University, University of Michigan) under the direction of PI Hakan Yilmaz and Co-PI Oliver Miersch-Wiemers, Robert Bosch LLC.

\section{DISCLAIMER}

This report was prepared as an account of work sponsored by an agency of the United States Government. Neither the United States Government nor any agency 
thereof, nor any of their employees, makes any warranty, express or implied, or assumes any legal liability or responsibility for the accuracy, completeness, or usefulness of any information, apparatus, product, or process disclosed, or represents that its use would not infringe privately owned rights. Reference herein to any specific commercial product, process, or service by trade name, trademark, manufacturer, or otherwise does not necessarily constitute or imply its endorsement, recommendation, or favoring by the United States Government or any agency thereof. The views and opinions of authors expressed herein do not necessarily state or reflect those of the United States Government or any agency thereof. 


\section{References}

[1] S. Onishi, S.H. Jo, K. Shoda, P.D. Jo, S. Kato, SAE Technical Paper 790501, 1979.

[2] M. Noguchi, Y. Tanaka, T. Tanaka, Y. Takeuchi, SAE Technical Paper 790840, 1979.

[3] P.M. Najt, D.E. Foster, SAE Technical Paper 830264, 1983.

[4] R.H. Thring, SAE Technical Paper 892068, 1989.

[5] G.A. Lavoie, J. Martz, M. Wooldridge, D. Assanis, Combust. Flame 157 (6) (2010) 1106-1110.

[6] J.E. Dec, Y. Yang, SAE Technical Paper 2010-01-1086, 2010.

[7] S. Mamalis, A. Babajimopoulos, O. Guralp, P. Najt, SAE Technical Paper 201201-1101, 2012.

[8] D.A. Rothamer, J.A. Snyder, R.K. Hanson, R.R. Steeper, R. Fitzgerald, Proc. Combust. Inst. 32 (2) (2009) 2869-2876.

[9] G. Kontarakis, N. Collings, T. Ma, SAE Technical Paper 2000-01-2870, 2000.

[10] L. Koopmans, I. Denbratt, SAE Technical Paper 2001-01-3610, 2001.

[11] J. Allen, D. Law, SAE Technical Paper 2002-01-0422, 2002.

[12] K. Hiraya, K. Hasegawa, T. Urushihara, A. Iiyama, T. Itoh, SAE Technical Paper 2002-01-0416, 2002.

[13] N. Milovanovic, R. Chen, J. Turner, SAE Technical Paper 2004-01-1899, 2004.

[14] L.M. Olesky, J. Vavra, D. Assanis, A. Babajimopoulos, J. Eng. Gas Turbines Power 134 (11) (2012) 112801.

[15] R. Sankaran, H.G. Im, Combust. Theor. Model. 9 (3) (2005) 417-432.

[16] R. Sankaran, H.G. Im, E.R. Hawkes, J. Chen, Proc. Combust. Inst. 30 (1) (2005) 875-882.

[17] J.H. Chen, E.R. Hawkes, R. Sankaran, S.D. Mason, H.G. Im, Combust. Flame 145 (1-2) (2006) 128-144.

[18] E.R. Hawkes, R. Sankaran, P.P. Pébay, J.H. Chen, Combust. Flame 145 (1-2) (2006) 145-159.

[19] G. Bansal, H.G. Im, Combust. Flame 158 (11) (2011) 2105-2112.

[20] Y. Zeldovich, Combust. Flame 39 (1980) 211-214.

[21] J.B. Martz, R.J. Middleton, G.A. Lavoie, A. Babajimopoulos, D.N. Assanis, Combust. Flame 158 (6) (2011) 1089-1096.

[22] R.J. Middleton, J.B. Martz, G.A. Lavoie, A. Babajimopoulos, D.N. Assanis, Combust. Flame 159 (10) (2012) 3146-3157

[23] J.B. Martz, G.A. Lavoie, H.G. Im, R.J. Middleton, A. Babajimopoulos, D.N. Assanis, Combust. Flame 159 (6) (2012) 2077-2086. 
[24] S.M. Aceves, D.L. Flowers, C.K. Westbrook, J.R. Smith, R.W. Dibble, M. Christensen, W.J. Pitz, B. Johansson, SAE Technical Paper 2000-01-0327, 2000.

[25] S.M. Aceves, D.L. Flowers, J. Martinez-Frias, J.R. Smith, C.K. Westbrook, W.J. Pitz, R.W. Dibble, J.F. Wright, W.C. Akinyemi, R.P. Hessel, SAE Technical Paper 2001-01-1027, 2001.

[26] S.M. Aceves, J. Martinez-Frias, D.L. Flowers, J.R. Smith, R.W. Dibble, J.F. Wright, R.P. Hessel, SAE Technical Paper 2001-01-3612, 2001.

[27] A. Babajimopoulos, D.N. Assanis, S.B. Fiveland, SAE Technical Paper 200201-2829, 2002.

[28] A. Babajimopoulos, G.A. Lavoie, D.N. Assanis, SAE Technical Paper 200301-3220, 2003.

[29] A. Babajimopoulos, D.N. Assanis, D.L. Flowers, S.M. Aceves, R.P. Hessel, Int. J. Engine Res. 6 (5) (2005) 497-512.

[30] J. Kodavasal, S. Keum, A. Babajimopoulos, Combust. Theor. Model. 15 (6) (2011) 893-910.

[31] J. Kodavasal, M.J. McNenly, A. Babajimopoulos, S.M. Aceves, D.N. Assanis, M.A. Havstad, D.L. Flowers, Int. J. Engine Res., 14 (5) (2013) 416-433.

[32] T. Joelsson, R. Yu, J. Sjöholm, P. Tunestal, X-.S. Bai, SAE Technical Paper 2010-01-2235, 2010.

[33] L.M. Olesky, J.B. Martz, G.A. Lavoie, J. Vavra, D.N. Assanis, A. Babajimopoulos, Appl. Energy 105 (2013) 407-411.

[34] A.A. Amsden, KIVA-3V: A Block Structured KIVA Program for Engines with Vertical or Canted Valves, Report No. LA-13313-MS, Los Alamos National Laboratory, 1997.

[35] A.W. Berntsson, I. Denbratt, SAE Technical Paper 2007-01-0210, 2007.

[36] Y. Yang, J.E. Dec., N. Dronniou, M. Sjöberg, Proc. Combust. Inst. 33 (2) (2011) 3047-3055.

[37] Y. Yang, J. Dec, N. Dronniou, M. Sjöberg, W. Cannella, SAE Technical Paper 2011-01-1359, 2011.

[38] B. Wolk, J.-Y. Chen, $8^{\text {th }}$ US National Combustion Meeting organized by the Western States Section of the Combustion Institute and hosted by the University of Utah, 2013.

[39] J. M. Krasselt, D. E. Foster, J. B. Ghandhi, R. E. Herold, D. L. Reuss, P. M. Najt, SAE Technical Paper 2009-01-1105, 2009.

[40] R. E. Herold, J. M. Krasselt, D. E. Foster, J. B. Ghandhi, D. L. Reuss, P. M. Najt, SAE Technical Paper 2009-01-1106, 2009.

[41] J. Kodavasal, G. A. Lavoie, D. N. Assanis, J. B. Martz, Spring Technical Meeting of the Central States of the Combustion Institute, Tulsa, OK, 2014.

[42] P.J. O'Rourke, A.A. Amsden, SAE Technical Paper 872089, 1987. 
[43] M. Mehl, J.Y. Chen, W.J. Pitz, S.M. Sarathy, C.K. Westbrook, Energy Fuels 25 (11) (2011) 5215-5223.

[44] M. Mehl, W.J. Pitz, C.K. Westbrook, H.J. Curran, Proc. Combust. Inst. 33 (1) (2011) 193-200.

[45] M. Mehl, W.J. Pitz, M. Sarathy, Y. Yang, J.E. Dec, SAE Technical Paper 2012-01-1109, 2012.

[46] S. Som, D. Longman, S. Aithal, R. Bair, M. Garcia, S. Quan, K.J. Richards, P.K. Senecal, T. Shethaji, M. Weber, SAE Technical Paper 2013-01-1095, 2013.

[47] J. Kodavasal, C. Kolodziej, S. Ciatti, S. Som, Submitted to the ASME 2014 Internal Combustion Engine Division Fall Technical Conference, Columbus, IN, October 19-22, 2014.

[48] J. Kodavasal, PhD thesis, University of Michigan, Ann Arbor, Michigan, USA, 2013.

[49] X. He, M.T. Donovan, B.T. Zigler, T.R. Palmer, S.M. Walton, M.S. Wooldridge, A. Atreya, Combust. Flame 142 (3) (2005) 266-275.

[50] S. S. Goldsborough, Combust. Flame 156 (6) 1248-1262.

[51] A. Babajimopoulos, V.S.S.P. Challa, G.A. Lavoie, D.N. Assanis, Proceedings of the ASME Internal Combustion Engine Division 2009 Spring Technical Conference, ICES2009-76103, 2009.

[52] J. Kodavasal, G.A. Lavoie, D.N. Assanis, J.B. Martz, Proc. Combust. Inst., In Press (2014), DOI: 10.1016/j.proci.2014.06.152. 
Table 1. UM-FFVA engine and CFD mesh specifications (all experiments and simulations were at $2000 \mathrm{RPM})$.

\begin{tabular}{lll}
\hline Parameter & Engine & CFD mesh \\
\hline Cylinder displacement (L) & 0.550 & 0.540 \\
Bore/Stroke (mm) & $86.0 / 94.6$ & $86.0 / 94.3$ \\
Connecting Rod Length (mm) & 152.2 & 152.2 \\
Compression Ratio & $12.50: 1$ & $12.53: 1$ \\
IVC/EVO & $130^{\circ} \mathrm{bTDC} / 148^{\circ} \mathrm{aTDC}$ & $130^{\circ} \mathrm{bTDC} / 148^{\circ} \mathrm{aTDC}$ \\
Swirl Ratio & 0.3 & 0.3 \\
\hline
\end{tabular}

Table 2. Gasoline surrogate composition taken from Mehl et al. [43].

\begin{tabular}{ll}
\hline Species & Mass Fraction \\
\hline iso-octane & 0.5413 \\
$n$-heptane & 0.1488 \\
toluene & 0.2738 \\
2-pentene & 0.0361 \\
\hline
\end{tabular}


Table 3. Operating conditions for simulations: PVO-eEGR versus NVO-iEGR dilution - simulated PFI indicates premixed fueling at intake was used to simulate PFI

\begin{tabular}{lll}
\hline Parameter & PVO-eEGR & NVO-iEGR \\
\hline Fueling & Simulated PFI & Simulated PFI \\
RPM & 2000 & 2000 \\
NVO & $0^{\circ} \mathrm{CA}$ & $157^{\circ} \mathrm{CA}$ \\
$\boldsymbol{\phi}_{\boldsymbol{F} \boldsymbol{O}}$ (mean) & 0.44 & 0.44 \\
$\chi_{\boldsymbol{O} \text { o2 }}($ mean $)$ & $15 \%$ & $15 \%$ \\
$T_{\text {in }}$ & $241^{\circ} \mathrm{C}$ & $98^{\circ} \mathrm{C}$ \\
Internal EGR & $7 \%$ & $42 \%$ \\
External EGR & $36 \%$ & $0 \%$ \\
Total EGR & $43 \%$ & $42 \%$ \\
\hline
\end{tabular}

Table 4. Residual and intake streams: NVO-iEGR

\begin{tabular}{lrrr}
\hline & Residual & Intake & Overall (IVC) \\
\hline Mass \% at IVC & 42 & 48 & 100 \\
$\boldsymbol{\phi}_{\text {Fo }}$ (mean) & 0.00 & 0.56 & 0.44 \\
$\chi_{\boldsymbol{O} \text { (mean) }}$ (mean & $7.8 \%$ & $20.7 \%$ & $15 \%$ \\
$T$ & $418^{\circ} \mathrm{C}$ (at IVO, \\
$\left.270^{\circ} \mathrm{bTDC}\right)$ & $98^{\circ} \mathrm{C}$ & $273^{\circ} \mathrm{C}$ \\
\hline
\end{tabular}


Table 5. Residual and intake streams: PVO-eEGR

\begin{tabular}{lrrr}
\hline & Residual & Intake & Overall (IVC) \\
\hline Mass \% at IVC & 7 & 93 & 100 \\
$\boldsymbol{\phi}_{\boldsymbol{F o}}$ (mean) & 0.00 & 0.46 & 0.44 \\
$\chi_{\text {o2 }}$ (mean) & $7.8 \%$ & $15.8 \%$ & $15 \%$ \\
$T$ & $421^{\circ} \mathrm{C} \mathrm{(at} \mathrm{IVO,}$ & $241^{\circ} \mathrm{C}$ & $273^{\circ} \mathrm{C}$ \\
\hline
\end{tabular}
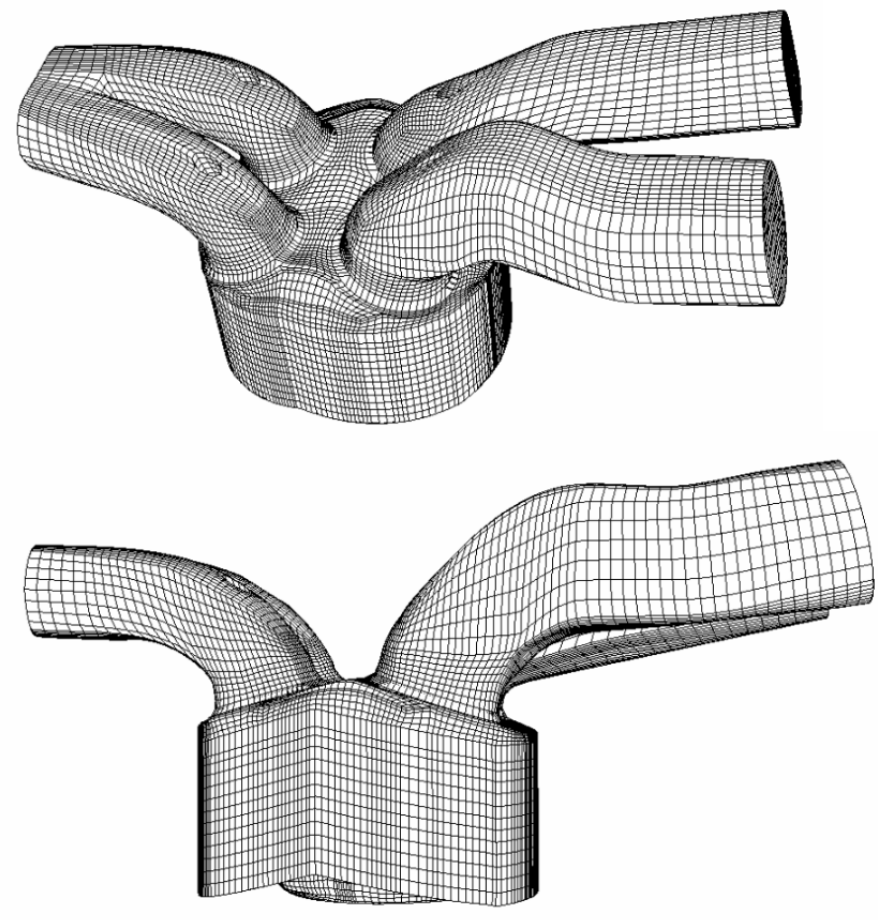

Figure 1. Computational mesh of the FFVA engine used in the simulations. 

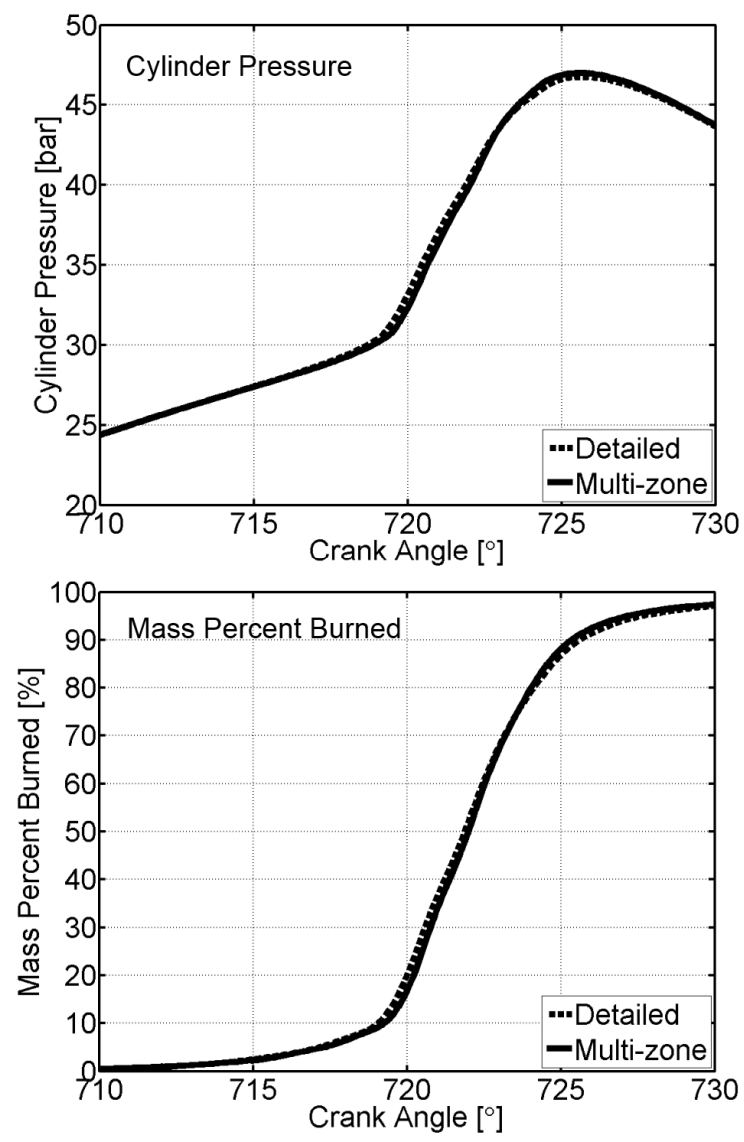

Figure 2. Evaluation of multi-zone model ( $5 \mathrm{~K}$ and $0.03 \varphi$ bins) performance against the detailed solution of chemistry in every CFD cell - in-cylinder pressure trace (top) and mass percentage burned (bottom) for a simulated case with direct injection at $30^{\circ}$ $\mathrm{CA}$ after gas-exchange TDC, and $157^{\circ} \mathrm{NVO}$. 

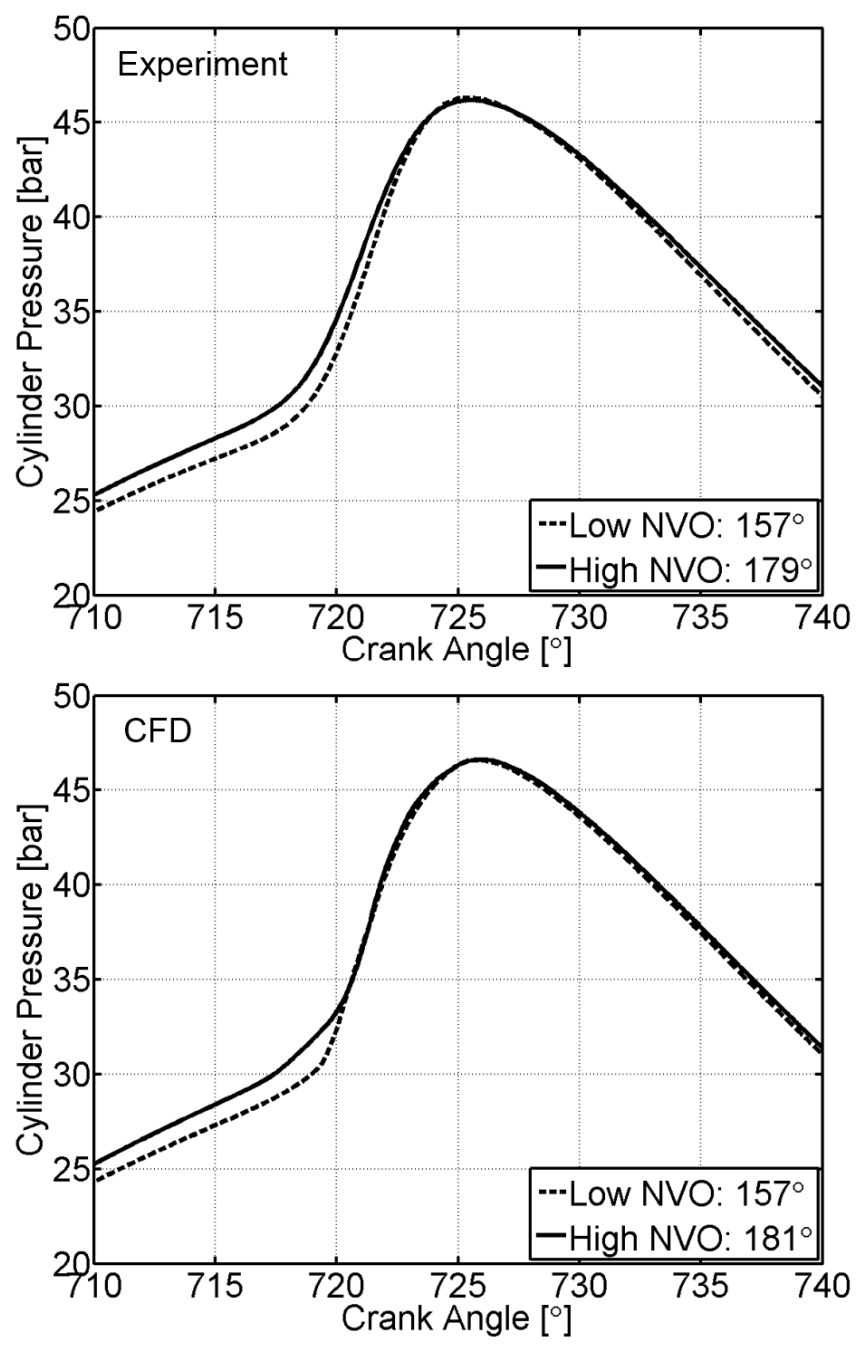

Figure 3. Comparison of in-cylinder pressure traces for the high and low NVO cases experiments and CFD results. Experiment: high $\mathrm{NVO}=179^{\circ}$, low $\mathrm{NVO}=157^{\circ}$;

CFD: high $\mathrm{NVO}=181^{\circ}$, low $\mathrm{NVO}=157^{\circ}$. 

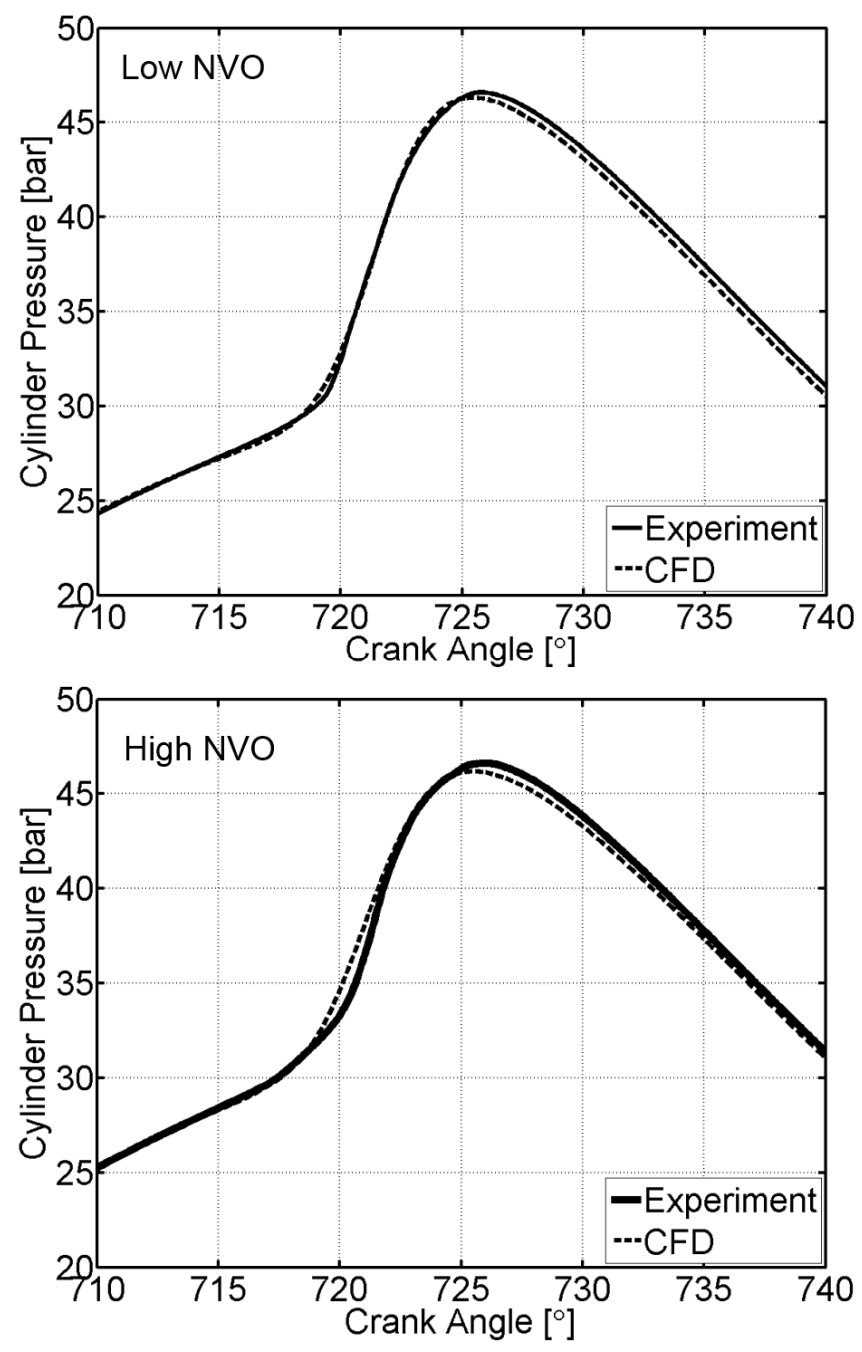

Figure 4. Comparison of in-cylinder pressure traces for the high and low NVO cases experiments and CFD results shown on top of each other. Experiment: high $\mathrm{NVO}=$ $179^{\circ}$, low $\mathrm{NVO}=157^{\circ} ; \mathrm{CFD}$ : high $\mathrm{NVO}=181^{\circ}$, low $\mathrm{NVO}=157^{\circ}$. 

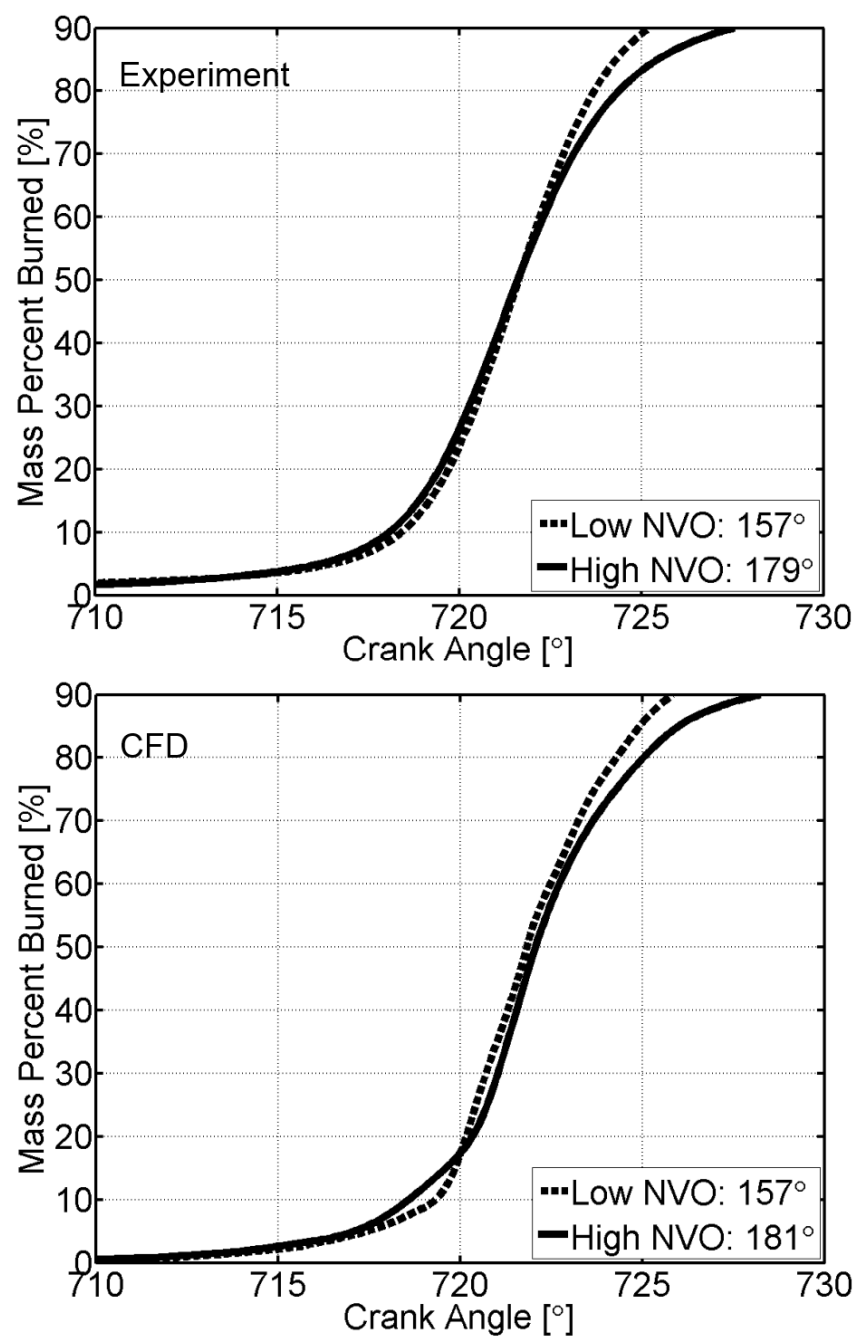

Figure 5. Comparison of the burn profiles for the high and low NVO cases experiments and CFD results. Experiment: high $\mathrm{NVO}=179^{\circ}$, low $\mathrm{NVO}=157^{\circ}$; $\mathrm{CFD}$ : high $\mathrm{NVO}=181^{\circ}$, low $\mathrm{NVO}=157^{\circ}$. The CFD reproduces the experimental trend of longer burn duration with increased NVO (higher amounts of internal residual) for a given ignition timing. 

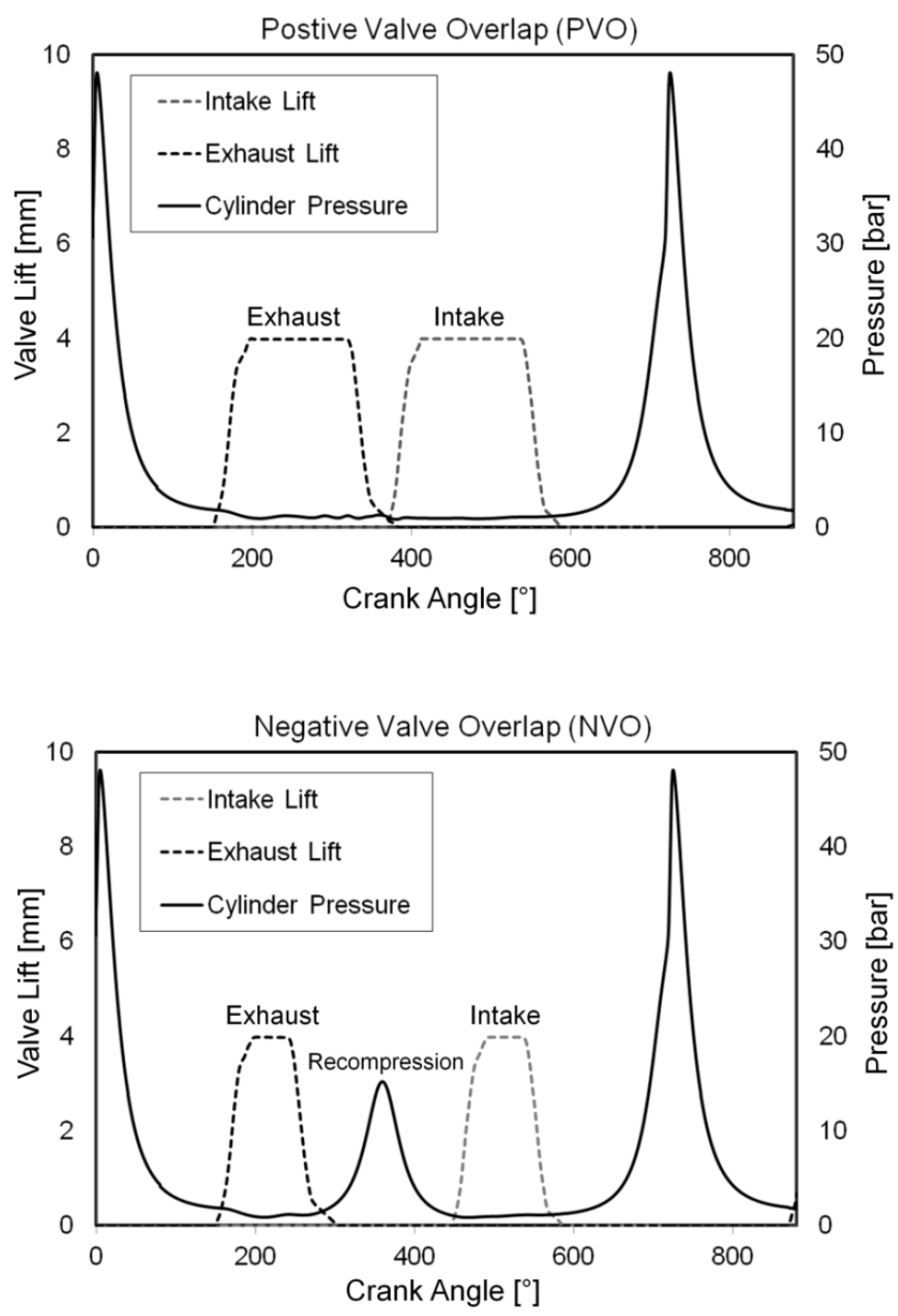

Figure 6. Positive valve overlap (PVO) and negative valve overlap (NVO) valve lift profiles used in this study shown with reference to a typical in-cylinder pressure trace. 


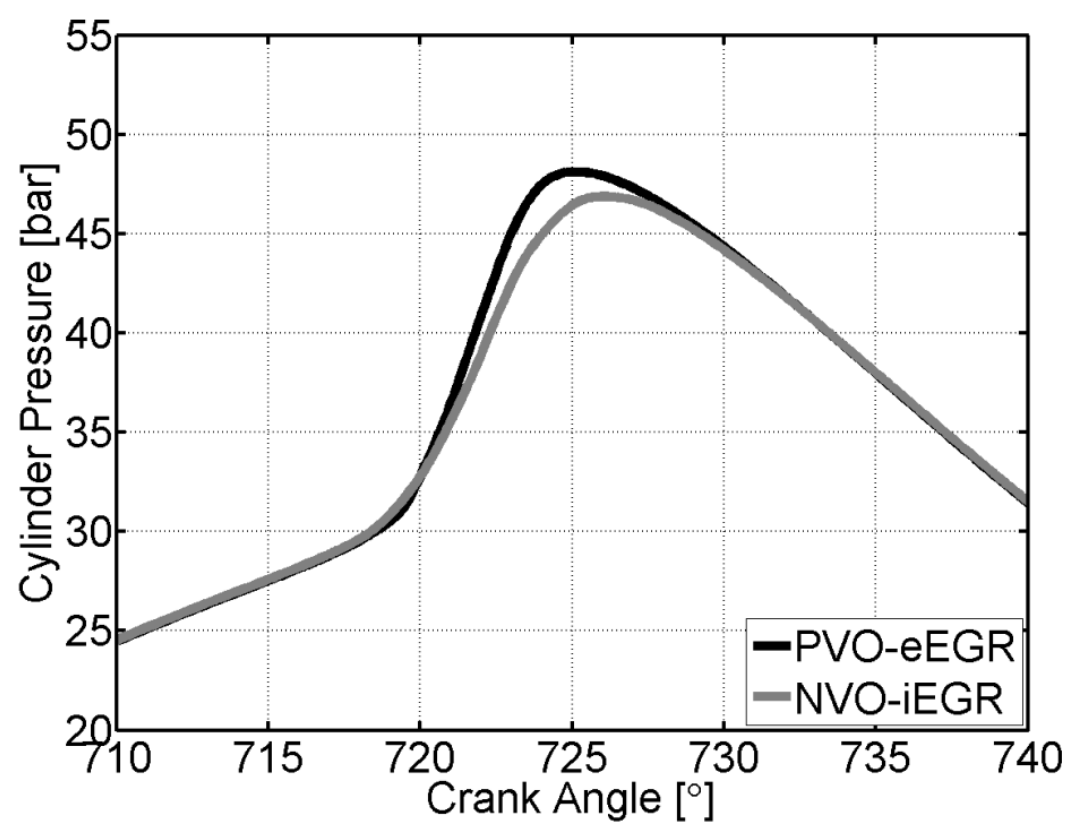

Figure 7. In-cylinder pressure traces from the CFD simulation of the PVO-eEGR case and the NVO-iEGR case.

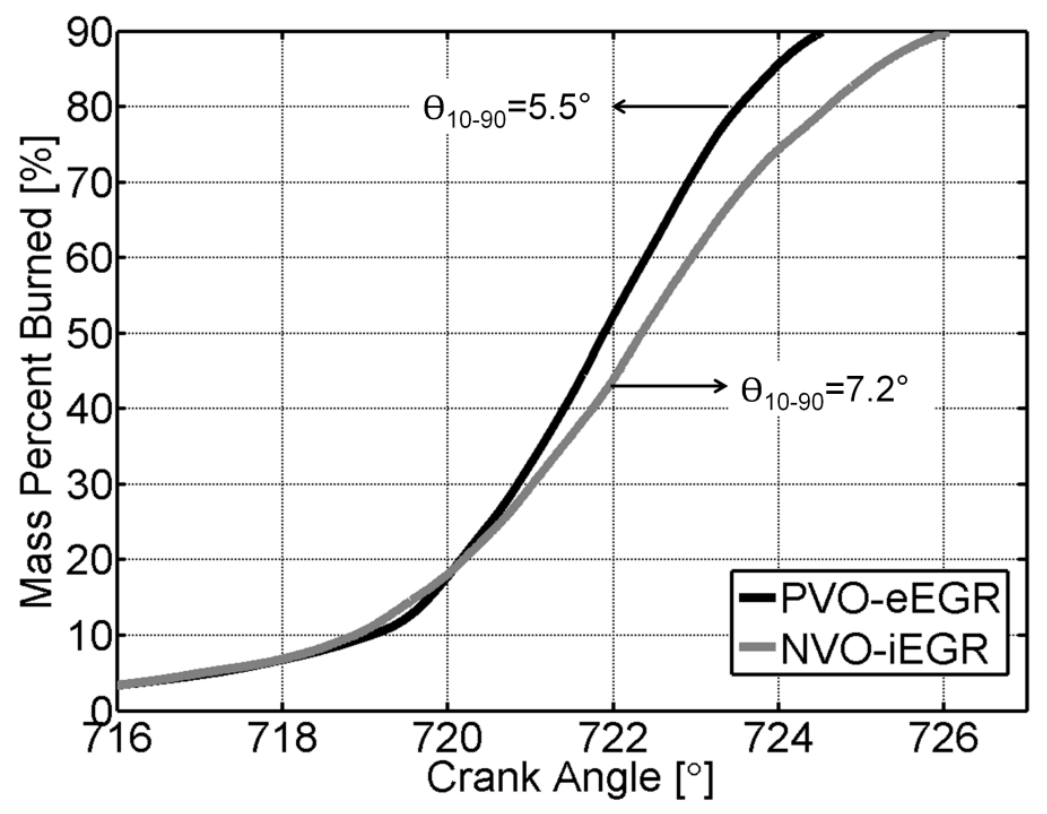

Figure 8. Burn profiles from the CFD simulation of the PVO-eEGR case and the NVO-iEGR case. The stratification brought about by NVO results in a $30 \%$ increase in burn duration for the same ignition timing and mean composition. 


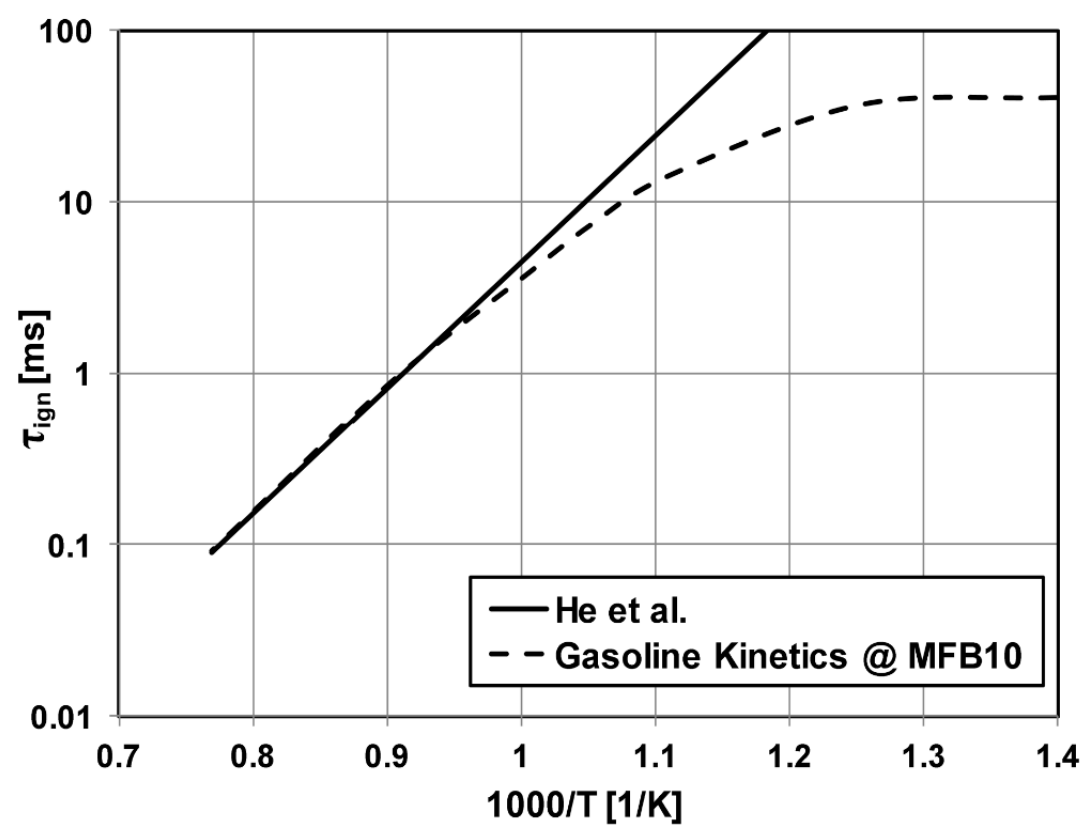

Figure 9. Comparison of ignition delay predictions based on the He et al. [49] correlation against ignition delay predictions (where ignition is considered at $10 \%$ mass fraction burned) from adiabatic, constant volume reactor simulations using the 312-species gasoline kinetics [43] under mean pre-ignition conditions (at $10^{\circ} \mathrm{CA}$ bTDC) corresponding to the CFD simulations. 

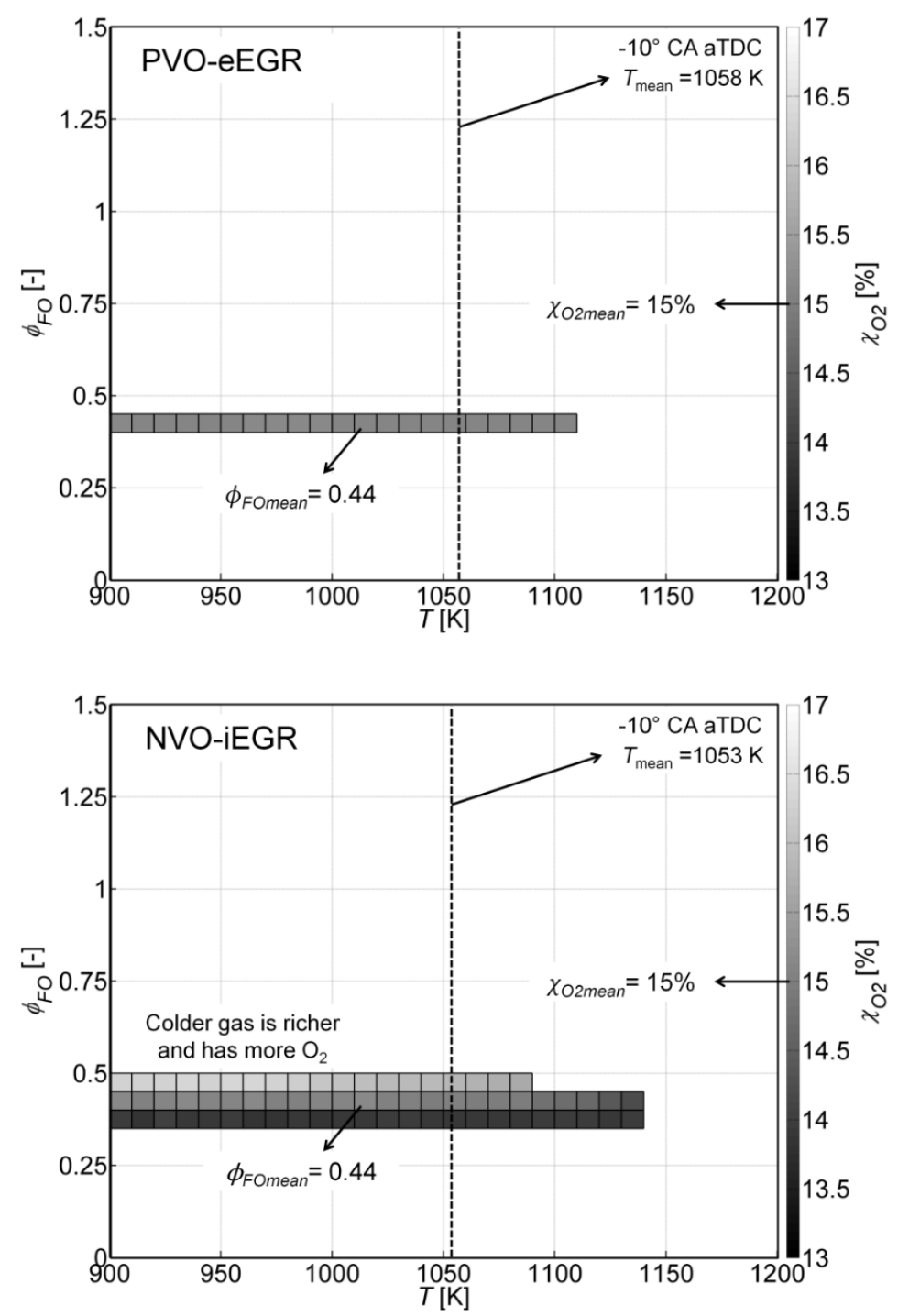

Figure 10. Pre-ignition $\left(10^{\circ} \mathrm{CA}\right.$ bTDC) reaction space from the CFD simulation visualized in terms of $\phi_{\mathrm{FO}}, \chi_{\mathrm{O} 2}$ and $T$. The PVO case has negligible stratification in composition $\left(\phi_{\mathrm{FO}}, \chi_{\mathrm{O} 2}\right)$, while the $\mathrm{NVO}$ case shows a visible compositional stratification in $\phi_{F O}$ and $\chi_{O 2}$ that is negatively correlated to temperature. 


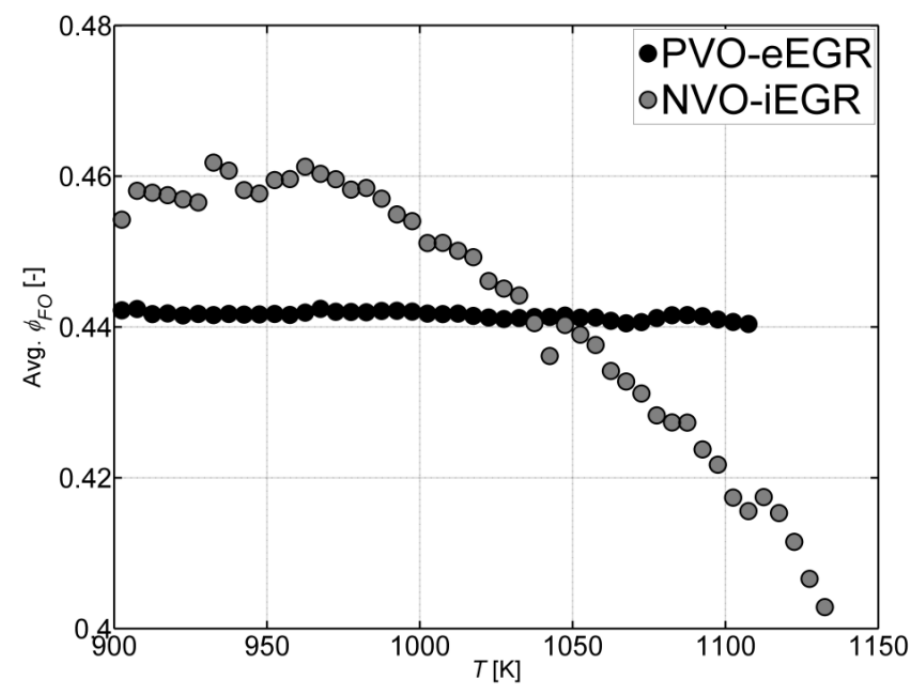

Figure 11. Pre-ignition $\left(10^{\circ} \mathrm{CA}\right.$ bTDC) distribution of the average $\phi_{F O}$ within a zone versus $T$. The PVO case has negligible stratification in $\phi_{F O}$, while the NVO case shows a negative correlation between $\phi_{F O}$ and $T$.

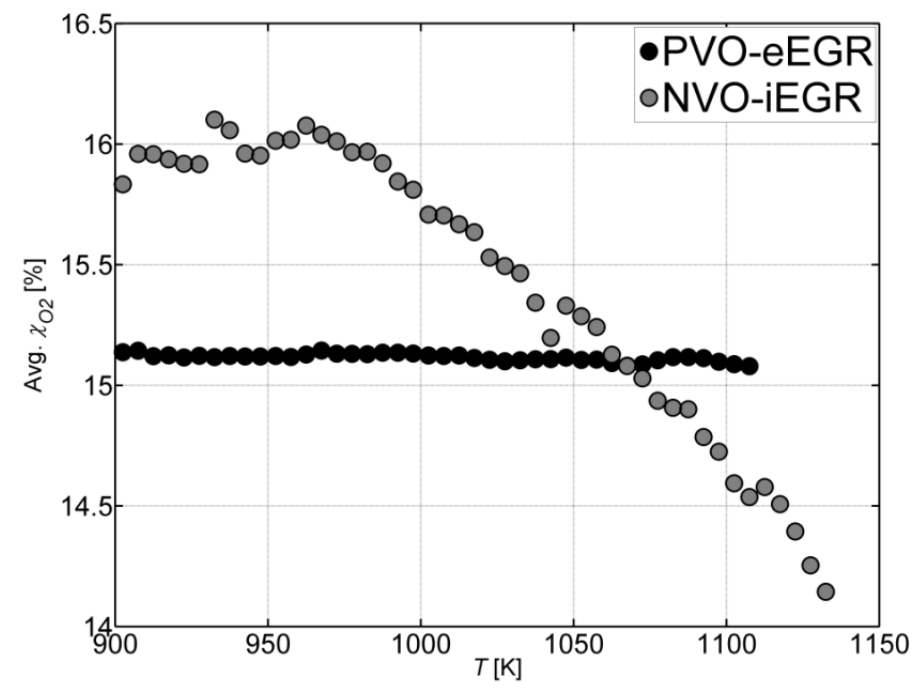

Figure 12. Pre-ignition $\left(10^{\circ} \mathrm{CA}\right.$ bTDC) distribution of the average $\chi_{O 2}$ within a zone versus $T$. The PVO case has negligible stratification in $\chi_{O 2}$, while the NVO case shows a negative correlation between $\chi_{O 2}$ and $T$. 


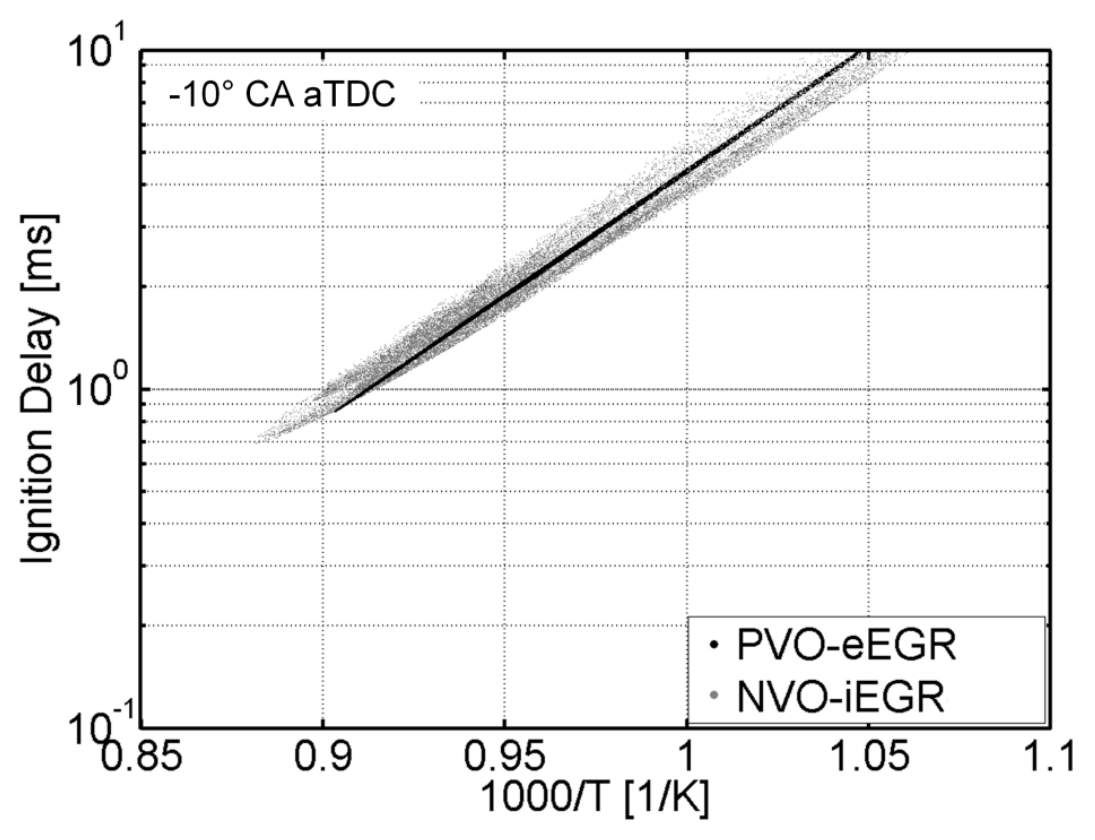

Figure 13. Ignition delay scatter from the $\mathrm{He}$ et al. correlation at pre-ignition $\left(10^{\circ} \mathrm{CA}\right.$ bTDC). At a given temperature, the PVO case shown in black has insignificant scatter in ignition delay due to minimal compositional stratification. The NVO case shown in grey has a small degree of scatter in ignition delay values for any given temperature resulting from compositional stratification. The ignition delay for both cases is primarily a function of temperature. 


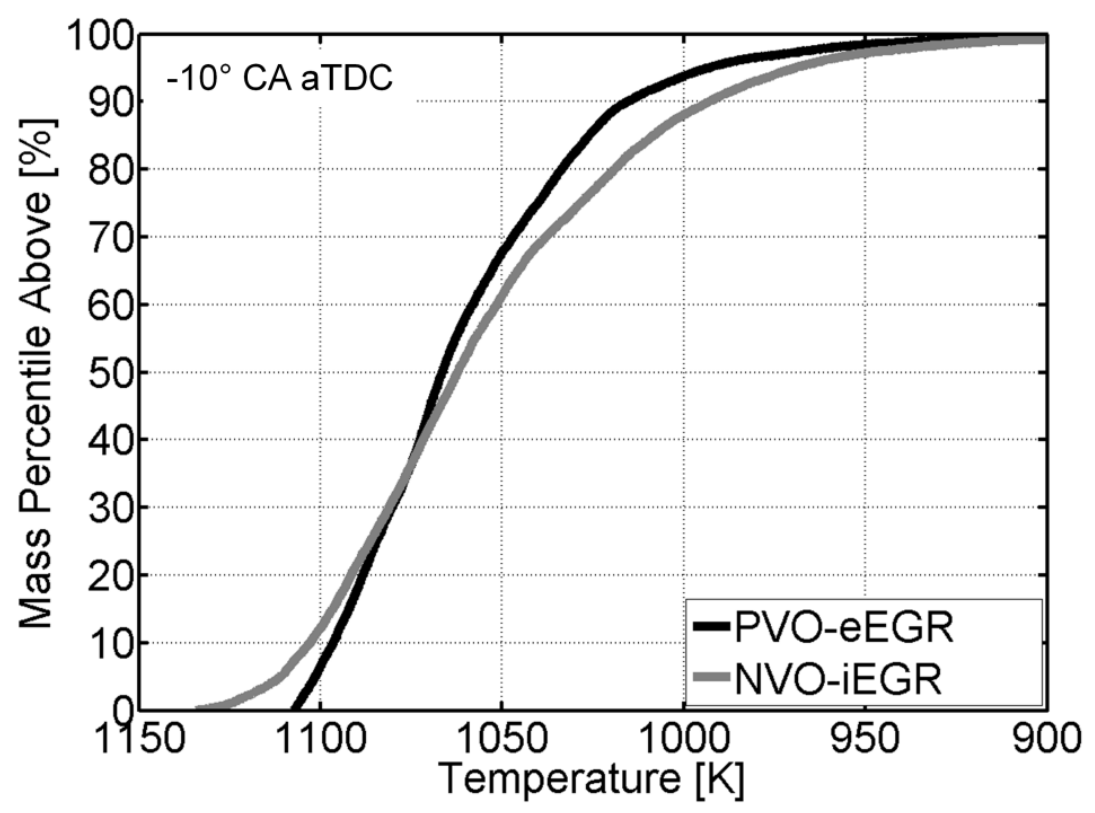

Figure 14. Pre-ignition ( $10^{\circ} \mathrm{CA}$ bTDC) cumulative temperature distribution from the CFD simulation of the PVO and NVO cases. Note how the leading edge of the temperature distribution is hotter for the NVO case, even though both cases ignite at the same time, showing that reactivity is not purely a function of temperature.

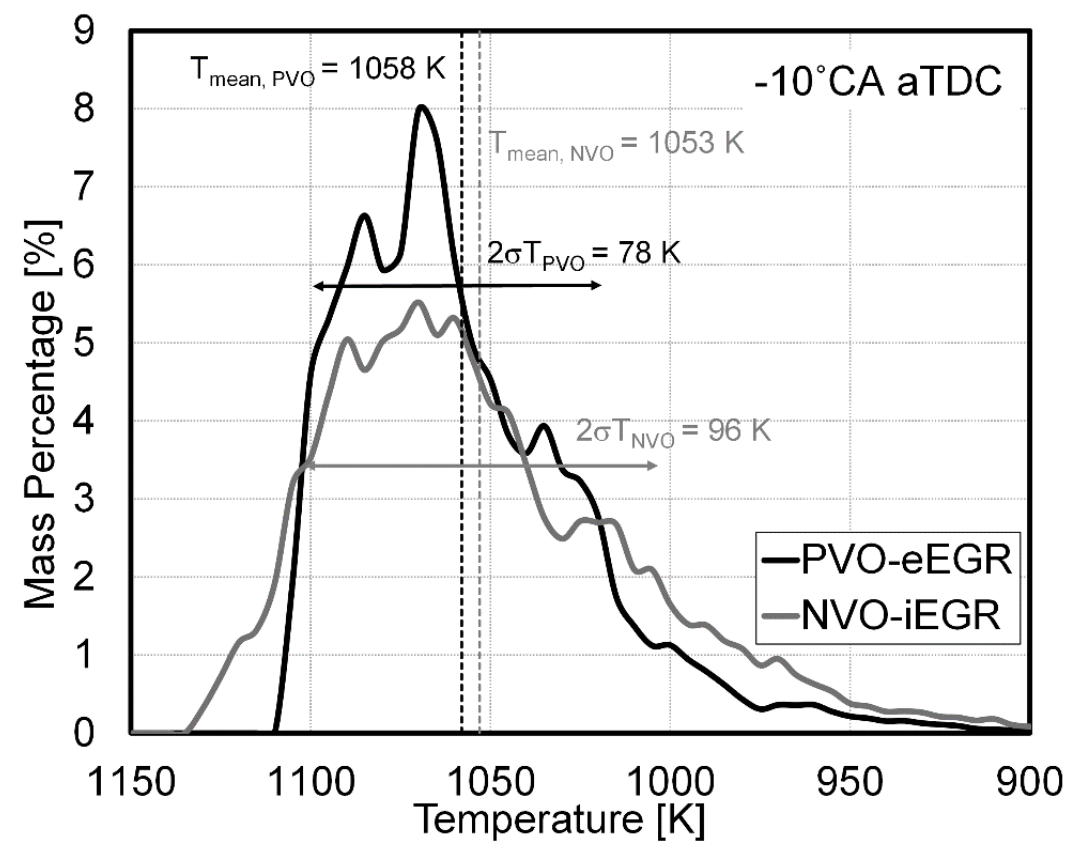

Figure 15 . Pre-ignition $\left(10^{\circ} \mathrm{CA}\right.$ bTDC) probability density function temperature distribution from the CFD simulation of the PVO and NVO cases showing the standard deviation in temperature. 


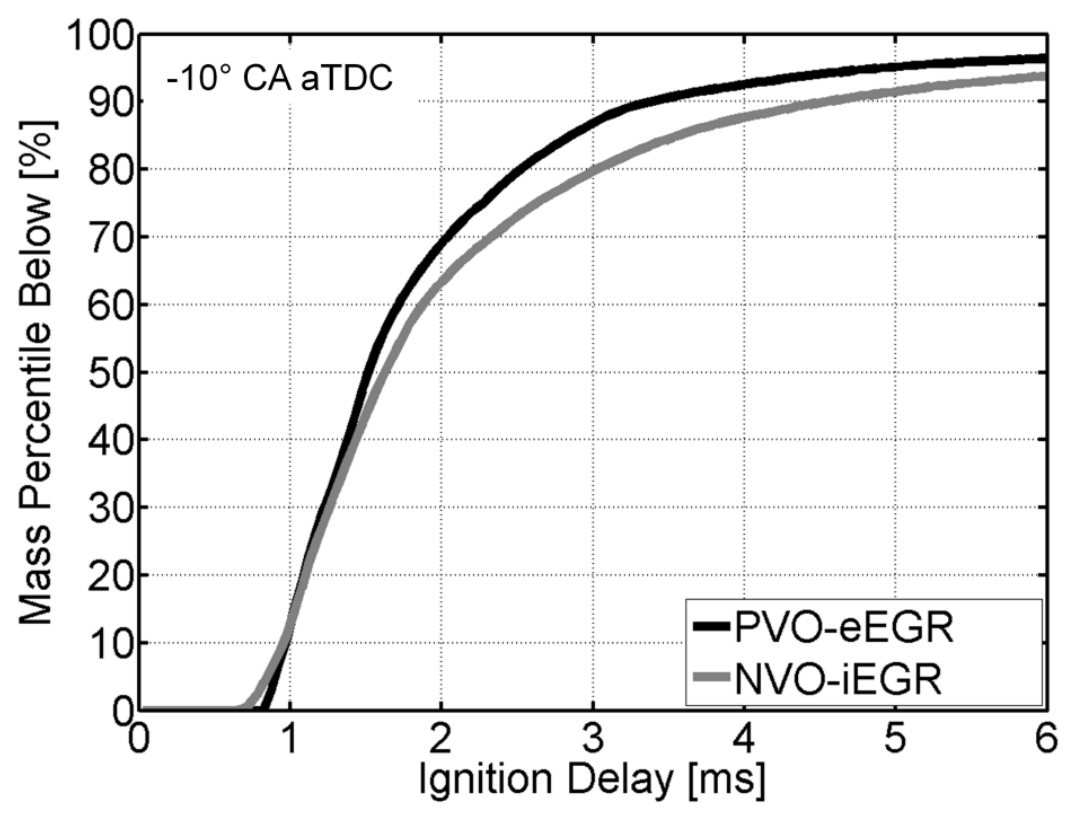

Figure 16. Cumulative reactivity distribution at pre-ignition $\left(10^{\circ} \mathrm{CA}\right.$ bTDC) from the CFD simulation. Note that the leading-edge of the distributions, represented by the most reactive $10 \%$ of charge mass (i.e. mass with ignition delays under $1 \mathrm{~ms}$ ), is matched for the PVO and NVO case, which is why both cases have the same CA10 ignition timing; however, the overall reactivity stratification (10-90 percentile) for the NVO case is larger than that of the PVO case. 


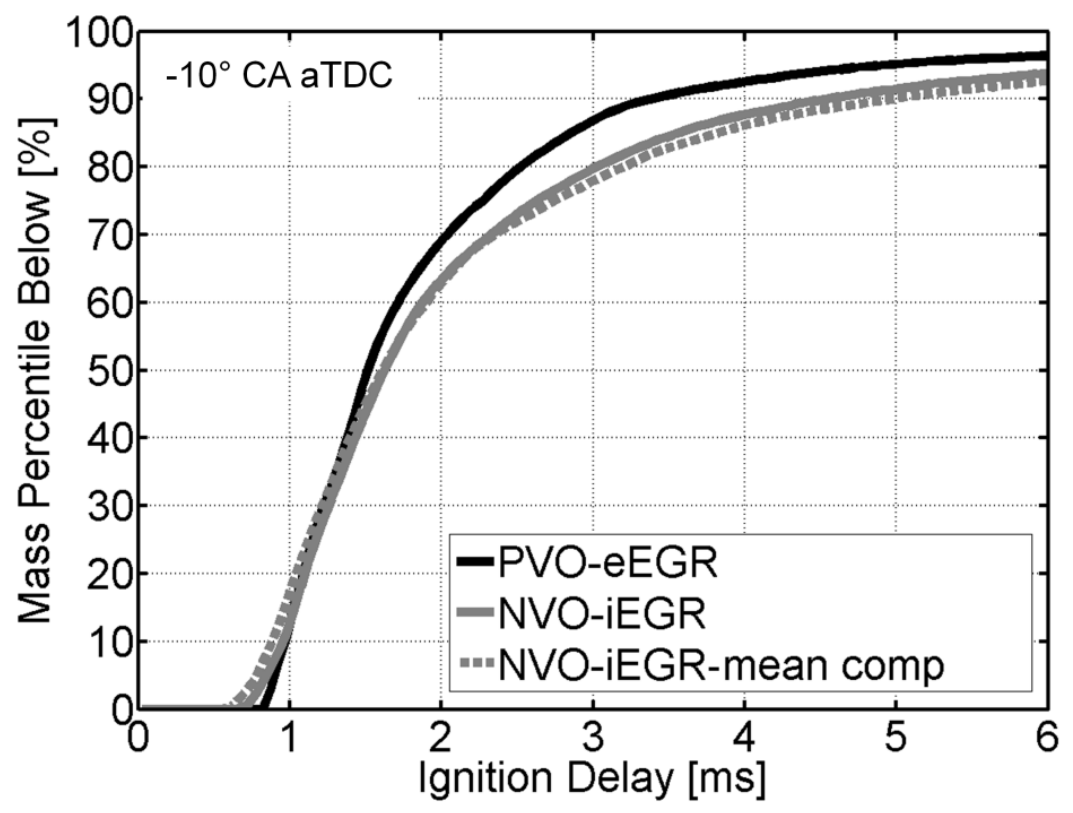

Figure 17. Cumulative reactivity distribution pre-ignition $\left(10^{\circ} \mathrm{CA}\right.$ bTDC) of three cases from the CFD simulation: PVO-eEGR, NVO-iEGR and NVO-iEGR with mean composition assumed in all cells. The figure shows that neglecting compositional stratification when computing the ignition delays within the cylinder (NVO-iEGRmean comp) does not significantly impact reactivity stratification (compared to NVOiEGR where compositional stratification is considered). 


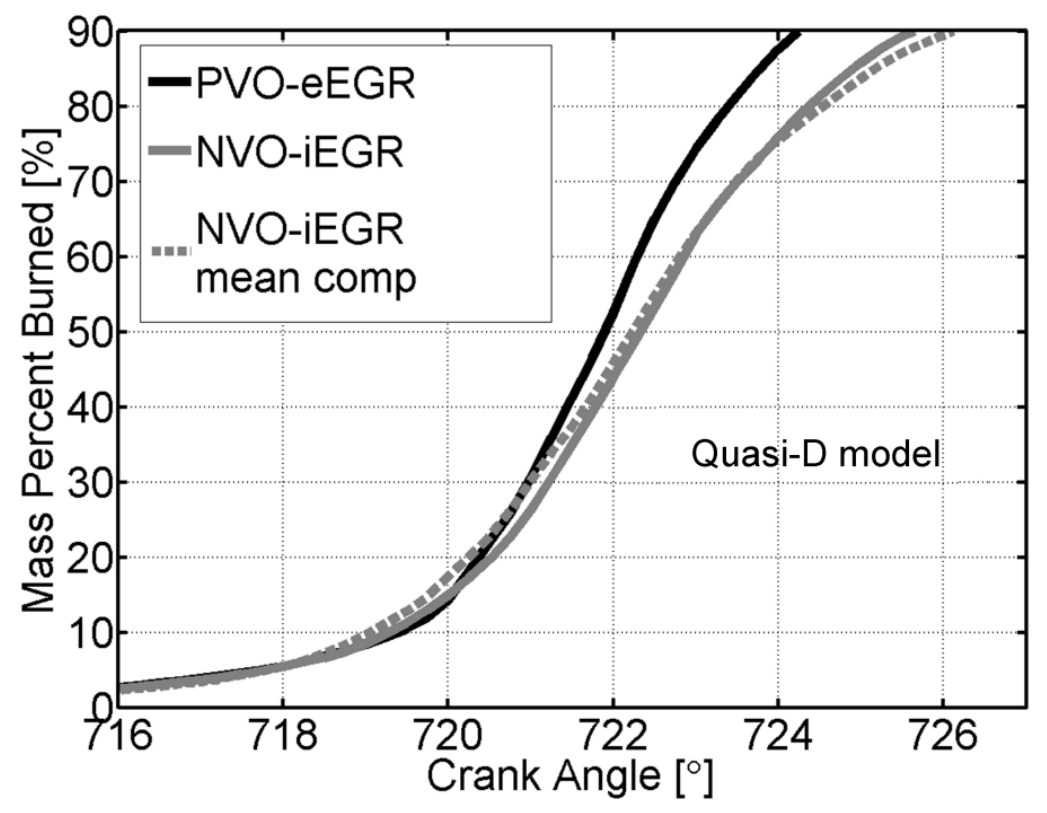

Figure 18. Mass percent burned predictions from the Quasi-D multi-zone model for PVO-eEGR, NVO-iEGR and NVO-iEGR with mean composition. The results indicate that neglecting compositional stratification (as in the NVO-iEGR-mean comp case which considers only thermal stratification) does not significantly impact the overall burn duration compared to the case where both compositional and thermal stratification are included. 